\title{
On the formulation of sea-ice models. Part 1: Effects of different solver implementations and parameterizations
}

\author{
Martin Losch ${ }^{\mathrm{a}, 1}$, Dimitris Menemenlis ${ }^{\mathrm{b}}$, Jean-Michel Campin ${ }^{\mathrm{c}}$, \\ Patick Heimbach ${ }^{\mathrm{c}}$, and Chris Hill ${ }^{\mathrm{c}}$ \\ ${ }^{a}$ Alfred-Wegener-Institut für Polar- und Meeresforschung, Postfach 120161, 27515 \\ Bremerhaven, Germany \\ ${ }^{\mathrm{b}}$ Jet Propulsion Laboratory, California Institute of Technology, 4800 Oak Grove \\ Drive, Pasadena, CA 91109, USA \\ ${ }^{\mathrm{c}}$ Department of Earth, Atmospheric, and Planetary Sciences, Massachusetts \\ Institute of Technology, 77 Massachusetts Avenue, Cambridge, MA 02139, USA
}

\begin{abstract}
This paper describes the sea ice component of the Massachusetts Institute of Technology general circulation model (MITgcm); it presents example Arctic and Antarctic results from a realistic, eddy-admitting, global ocean and sea ice configuration; and it compares B-grid and C-grid dynamic solvers and other numerical details of the parameterized dynamics and thermodynamics in a regional Arctic configuration. Ice mechanics follow a viscous-plastic rheology and the ice momentum equations are solved numerically using either line-successive-over-relaxation (LSOR) or elastic-viscous-plastic (EVP) dynamic models. Ice thermodynamics are represented using either a zero-heat-capacity formulation or a two-layer formulation that conserves enthalpy. The model includes prognostic variables for snow thickness and for sea ice salinity. The above sea ice model components were borrowed from currentgeneration climate models but they were reformulated on an Arakawa $\mathrm{C}$ grid in order to match the MITgcm oceanic grid and they were modified in many ways to permit efficient and accurate automatic differentiation. Both stress tensor divergence and advective terms are discretized with the finite-volume method. The choice of the dynamic solver has a considerable effect on the solution; this effect can be larger than, for example, the choice of lateral boundary conditions, of ice rheology, and of ice-ocean stress coupling. The solutions obtained with different dynamic solvers typically differ by a few $\mathrm{cm} \mathrm{s}^{-1}$ in ice drift speeds, $50 \mathrm{~cm}$ in ice thickness, and order $200 \mathrm{~km}^{3} \mathrm{yr}^{-1}$ in freshwater (ice and snow) export out of the Arctic.
\end{abstract}

Key words: NUMERICAL SEA ICE MODELING, VISCOUS-PLASTIC RHEOLOGY, EVP, COUPLED OCEAN AND SEA ICE MODEL, STATE 


\section{Introduction}

1 corresponding author, email: Martin.Losch@awi.de, ph: ++49 (471) 4831-1872, fax: ++49 (471) 4831-1797

It is widely recognized that high-latitude processes are an important component of the climate system (Lemke et al., 2007, Serreze et al., 2007). As a consequence, these processes need to be accurately represented in climate state estimates and in predictive models. Sea ice, though only a thin layer between the air and the sea, has strong and numerous influences within the climate system; it influences radiation balance due to its high albedo, surface heat and mass fluxes due to its insulating properties, freshwater fluxes due to transport and ablation, ocean mixed layer processes, and human operations. Sea ice variability and long term trends are distinctly different in the polar regions of the Northern and of the Southern hemispheres (Cavalieri and Parkinson, 2008, Parkinson and Cavalieri, 2008). These differences and their interaction with the global climate system are still poorly represented in state-of-the-art general circulation models (Holloway et al., 2007, Kwok et al., 2008). In addition, the atmospheric and oceanic states, which are needed to drive sea ice models, are still highly uncertain. Sea ice in turn constrains the state of both ocean and atmosphere near the surface so that observations of sea ice contain valuable information about the state of the coupled system. One way to reduce the model and boundary-condition uncertainties and to improve the representation of coupled ocean and sea ice processes is via coupled ocean and sea ice state estimation, that is, by using ocean and sea ice data to constrain a numerical model of the coupled system in order to obtain a dynamically consistent ocean and sea ice state with closed property budgets.

This paper describes a new sea ice model designed to be used for coupled ocean and sea ice state estimation. While many of its features are "conventional" (yet for the most part state-of-the-art), the model is different from previous models in that it is tailored for the generation of efficient adjoint code for coupled ocean and sea ice simulations by means of automatic (or algorithmic) differentiation (AD, Griewank, 2000). Sensitivity propagation in coupled systems is highly desirable as it permits both ocean and sea ice observations to be used as simultaneous constraints, leading to a truly coupled estimation problem. For example this approach is being used in planetary scale ocean and sea-ice monitoring and measuring activities, such as Heimbach (2008), Stammer et al. 
(2002) and Menemenlis et al. (2005).

Our work is presented in two parts. Part 1 (this paper) outlines the dynamic and thermodynamic sea ice model that has been coupled to the MITgcm ocean, with special emphasis on examining the influence of sea-ice rheology solvers and on model behavior. Part 2 (a companion paper) is devoted to the development of an efficient and accurate coupled ocean and sea ice adjoint model by means of automatic differentiation and to using adjoint sensitivity calculations to understand model sea ice dynamics.

Most standard sea-ice models are discretized on Arakawa B grids (e.g., Hibler, 1979, Harder and Fischer, 1999, Kreyscher et al., 2000, Zhang et al., 1998, Hunke and Dukowicz, 1997), probably because early numerical ocean models were formulated on the Arakawa B grid and because of the easier (implicit) treatment of the Coriolis term. As model resolution increases, more and more ocean and sea ice models use an Arakawa C grid discretization (e.g., Marshall et al., 1997a, Ip et al., 1991, Tremblay and Mysak, 1997, Lemieux et al., 2008, Bouillon et al., 2009). The new MITgcm sea ice model is formulated on an Arakawa C grid, and two different solvers (LSOR and EVP) are implemented; a previous version of the LSOR solver on a B grid is also available. It is used here for comparison with the new $\mathrm{C}$ grid implementation.

From the perspective of coupling a sea ice-model to a C-grid ocean model, the exchange of fluxes of heat and freshwater pose no difficulty for a B-grid sea ice model (e.g., Timmermann et al., 2002). Surface stress, however, is defined at velocity points and thus needs to be interpolated between a B-grid sea ice model and a C-grid ocean model. Smoothing implicitly associated with this interpolation may mask grid scale noise and may contribute to stabilizing the solution. Additionally, the stress signals are damped by smoothing, which may lead to reduced variability of the system. By choosing a $\mathrm{C}$ grid for the sea-ice model, we avoid this difficulty altogether and render the stress coupling as consistent as the buoyancy flux coupling.

A further characteristic of the C-grid formulation is apparent in narrow straits. In the limit of only one grid cell between coasts, there is no flux allowed for a B grid (with no-slip lateral boundary conditions, which are natural for the B grid) and models have used topographies with artificially widened straits in order to avoid this problem (Holloway et al., 2007). The C-grid formulation, however, allows a flux through narrow passages even if no-slip boundary conditions are imposed (Bouillon et al., 2009). We examine the quantitative impact of this effect in the Canadian Arctic Archipelago (CAA) by exploring differences between the solutions obtained on either the $\mathrm{B}$ or the $\mathrm{C}$ grid, with either the LSOR or the EVP solver, and under various options for lateral boundary conditions (free-slip vs. no-slip). Compared to the study of Bouillon et al. (2009), which was carried out using a grid with minimum horizontal grid 
spacing of $65 \mathrm{~km}$ in the Arctic Ocean, this study includes discussion of the LSOR solver and the sensitivity experiments are carried out on an Arctic grid with uniform 18-km horizontal grid spacing.

The remainder of this paper is organized as follows. Section 2 describes the dynamics and thermodynamics components, which have been incorporated in the MITgcm sea ice model. Section 3 presents example Arctic and Antarctic results from a realistic, eddy-admitting, global ocean and sea ice configuration. Section 4 compares B-grid and C-grid dynamic solvers under different lateral boundary conditions and investigates other numerical details of the parameterized dynamics and thermodynamics in a regional Arctic configuration. Discussion and conclusions follow in Section 5.

\section{Sea ice model formulation}

The MITgcm sea ice model is based on a variant of the viscous-plastic (VP) dynamic-thermodynamic sea-ice model of Zhang and Hibler (1997) first introduced by Hibler $(1979,1980)$. Many aspects of the original codes have been adapted; these are the most important ones:

- the model has been rewritten for an Arakawa C grid, both B- and C-grid variants are available; the finite-volume $\mathrm{C}$-grid code allows for no-slip and free-slip lateral boundary conditions,

- two different solution methods for solving the nonlinear momentum equations, LSOR (Zhang and Hibler, 1997) and EVP (Hunke, 2001, Hunke and Dukowicz, 2002), have been adopted,

- ice-ocean stress can be formulated as in Hibler and Bryan (1987) as an alternative to the standard method of applying ice-ocean stress directly,

- ice concentration and thickness, snow, and ice salinity or enthalpy can be advected by sophisticated, conservative advection schemes with flux limiters.

The sea ice model is tightly coupled to the ocean component of the MITgcm (Marshall et al., 1997b,a). Heat, freshwater fluxes and surface stresses are computed from the atmospheric state and modified by the ice model at every time step. The remainder of this section describes the model equations and details of their numerical realization. Further documentation and model code can be found at http://mitgcm.org. 
Sea-ice motion is driven by ice-atmosphere, ice-ocean and internal stresses; and by the horizontal surface elevation gradient of the ocean. The internal stresses are evaluated following a viscous-plastic (VP) constitutive law with an elliptic yield curve as in Hibler (1979). The full momentum equations for the sea-ice model and the solution by line successive over-relaxation (LSOR) are described in Zhang and Hibler (1997). Implicit solvers such as LSOR usually require capping very high viscosities for numerical stability reasons. Alternatively, the elastic-viscous-plastic (EVP) technique following Hunke (2001) regularizes large viscosities by adding an extra term in the constitutive law that introduces damped elastic waves. The EVP-solver relaxes the ice state towards the VP rheology by sub-cycling the evolution equations for the internal stress tensor components and the sea ice momentum solver within one ocean model time step. Neither solver requires limiting the viscosities from below (see Appendix A for details).

For stress tensor computations the replacement pressure (Hibler and Ip, 1995) is used so that the stress state always lies within the elliptic yield curve by definition. In an alternative to the elliptic yield curve, the so-called truncated ellipse method (TEM), the shear viscosity is capped to suppress any tensile stress (Hibler and Schulson, 1997, Geiger et al., 1998).

The horizontal gradient of the ocean's surface is estimated directly from ocean sea surface height and pressure loading from atmosphere, ice and snow (Campin et al., 2008). Ice does not float on top of the ocean, instead it depresses the ocean surface according to its thickness and buoyancy.

Lateral boundary conditions are naturally "no-slip" for B grids, as the tangential velocities points lie on the boundary. For $\mathrm{C}$ grids, the lateral boundary condition for tangential velocities allow alternatively no-slip or free-slip conditions. In ocean models free-slip boundary conditions in conjunction with piecewise-constant ("castellated") coastlines have been shown to reduce to no-slip boundary conditions (Adcroft and Marshall, 1998); for coupled ocean sea-ice models the effects of lateral boundary conditions have not yet been studied (as far as we know). Free-slip boundary conditions are not implemented for the B grid.

Moving sea ice exerts a surface stress on the ocean. In coupling the sea-ice model to the ocean model, this stress is applied directly to the surface layer of the ocean model. An alternative ocean stress formulation is given by Hibler and Bryan (1987). Rather than applying the interfacial stress directly, the stress is derived from integrating over the ice thickness to the bottom of the oceanic surface layer. In the resulting equation for the combined ocean-ice 
momentum, the interfacial stress cancels and the total stress appears as the sum of wind stress and divergence of internal ice stresses (see also Eq. 2 of Hibler and Bryan, 1987). While this formulation tightly embeds the sea ice into the surface layer of the ocean, its disadvantage is that the velocity in the surface layer of the ocean that is used to advect ocean tracers is an average over the ocean surface velocity and the ice velocity, leading to an inconsistency as the ice temperature and salinity are different from the oceanic variables. Both stress coupling options are available for a direct comparison of their effects on the sea-ice solution.

The finite-volume discretization of the momentum equation on the Arakawa $\mathrm{C}$ grid is straightforward. The stress tensor divergence, in particular, is discretized naturally on the $\mathrm{C}$ grid with the diagonal components of the stress tensor on the center points and the off-diagonal term on the corner (or vorticity) points of the grid. With this choice all derivatives are discretized as central differences and very little averaging is involved (see Appendix B for details). Apart from the standard C-grid implementation, the original B-grid implementation of Zhang and Hibler (1997) is also available as an option in the code.

\subsection{Thermodynamics}

Upward conductive heat flux through the ice is parameterized assuming a linear temperature profile and a constant ice conductivity implying zero heat capacity for ice. This type of model is often referred to as a "zero-layer" model (Semtner, 1976). The surface heat flux is computed in a similar way to that of Parkinson and Washington (1979) and Manabe et al. (1979).

The conductive heat flux depends strongly on the ice thickness $h$. However, the ice thickness in the model represents a mean over a potentially very heterogeneous thickness distribution. In order to parameterize a sub-grid scale distribution for heat flux computations, the mean ice thickness $h$ is split into seven thickness categories $H_{n}$ that are equally distributed between $2 h$ and a minimum imposed ice thickness of $5 \mathrm{~cm}$ by $H_{n}=\frac{2 n-1}{7} h$ for $n \in[1,7]$. The heat fluxes computed for each thickness category are area-averaged to give the total heat flux (Hibler, 1984).

The atmospheric heat flux is balanced by an oceanic heat flux. The oceanic flux is proportional to the difference between ocean surface temperature and the freezing point temperature of seawater, which is a function of salinity. This flux is not assumed to instantaneously melt or create ice, but a time scale of three days is used to relax the ocean temperature to the freezing point. While this parameterization is not new (it follows the ideas of, e.g., Mellor et al., 
1986, McPhee, 1992, Lohmann and Gerdes, 1998, Notz et al., 2003), it avoids a discontinuity in the functional relationship between model variables, which improves the smoothness of the differentiated model (see Fenty, 2010, for details). The parameterization of lateral and vertical growth of sea ice follows that of Hibler $(1979,1980)$.

On top of the ice there is a layer of snow that modifies the heat flux and the albedo as in Zhang et al. (1998). If enough snow accumulates so that its weight submerges the ice and the snow is flooded, a simple mass conserving parameterization of snow ice formation (a flood-freeze algorithm following Archimedes' principle) turns snow into ice until the ice surface is back at sea-level (Leppäranta, 1983).

The concentration $c$, effective ice thickness (ice volume per unit area, $c \cdot h$ ), effective snow thickness $\left(c \cdot h_{s}\right)$, and effective ice salinity $\left(\right.$ in $\left.\mathrm{g} \mathrm{m}^{-2}\right)$ are advected by ice velocities. From the various advection schemes that are available in the MITgcm (MITgcm Group, 2002), we choose flux-limited schemes, that is, multidimensional 2nd and 3rd-order advection schemes with flux limiters (Roe, 1985, Hundsdorfer and Trompert, 1994), to preserve sharp gradients and edges that are typical of sea ice distributions and to rule out unphysical over- and undershoots (negative thickness or concentration). These schemes conserve volume and horizontal area and are unconditionally stable, so that no extra diffusion is required.

There is considerable doubt about the reliability of a "zero-layer" thermodynamic model - Semtner (1984) found significant errors in phase (one month lead) and amplitude ( $\approx 50 \%$ overestimate) in such models — so that today many sea ice models employ more complex thermodynamics. The MITgcm sea ice model provides the option to use the thermodynamics model of Winton (2000), which in turn is based on the 3-layer model of Semtner (1976) and which treats brine content by means of enthalpy conservation. This scheme requires additional state variables, namely the enthalpy of the two ice layers (instead of effective ice salinity), to be advected by ice velocities. The internal sea ice temperature is inferred from ice enthalpy. To avoid unphysical (negative) values for ice thickness and concentration, a positive 2nd-order advection scheme with a SuperBee flux limiter (Roe, 1985) is used in this study to advect all sea-ice-related quantities of the Winton (2000) thermodynamic model. Because of the non-linearity of the advection scheme, care must be taken in advecting these quantities: when simply using ice velocity to advect enthalpy, the total energy (i.e., the volume integral of enthalpy) is not conserved. Alternatively, one can advect the energy content (i.e., product of ice-volume and enthalpy) but then false enthalpy extrema can occur, which then leads to unrealistic ice temperature. In the currently implemented solution, the sea-ice mass flux is used to advect the enthalpy in order to ensure conservation of enthalpy and to prevent false enthalpy extrema. 
In Section 3 and 4 we exercise and compare several of the options, which have been discussed above; we intercompare the impact of the different formulations (all of which are widely used in sea ice modeling today) on Arctic sea ice simulation (Proshutinsky and Kowalik, 2007).

\section{Global Ocean and Sea Ice Simulation}

One example application of the MITgcm sea ice model is the eddy-admitting, global ocean and sea ice state estimates, which are being generated by the Estimating the Circulation and Climate of the Ocean, Phase II (ECCO2) project (Menemenlis et al., 2005). One particular, unconstrained ECCO2 simulation, labeled cube76, provides the baseline solution and the lateral boundary conditions for all the numerical experiments carried out in Section 4. Figure 1 shows representative sea ice results from this simulation.

The simulation is integrated on a cubed-sphere grid, permitting relatively even grid spacing throughout the domain and avoiding polar singularities (Adcroft et al., 2004). Each face of the cube comprises 510 by 510 grid cells for a mean horizontal grid spacing of $18 \mathrm{~km}$. There are 50 vertical levels ranging in thickness from $10 \mathrm{~m}$ near the surface to approximately $450 \mathrm{~m}$ at a maximum model depth of $6150 \mathrm{~m}$. The model employs the rescaled vertical coordinate " $\mathrm{z}$ " (Adcroft and Campin, 2004) with partial-cell formulation of Adcroft et al. (1997), which permits accurate representation of the bathymetry. Bathymetry is from the S2004 (W. Smith, unpublished) blend of the Smith and Sandwell (1997) and the General Bathymetric Charts of the Oceans (GEBCO) one arcminute bathymetric grid. In the ocean, the non-linear equation of state of Jackett and McDougall (1995) is used. Vertical mixing follows Large et al. (1994) but with meridionally and vertically varying background vertical diffusivity; at the surface, vertical diffusivity is $4.4 \times 10^{-6} \mathrm{~m}^{2} \mathrm{~s}^{-1}$ at the Equator, $3.6 \times 10^{-6} \mathrm{~m}^{2} \mathrm{~s}^{-1}$ north of $70^{\circ} \mathrm{N}$, and $1.9 \times 10^{-5} \mathrm{~m}^{2} \mathrm{~s}^{-1}$ south of $30^{\circ} \mathrm{S}$ and between $30^{\circ} \mathrm{N}$ and $60^{\circ} \mathrm{N}$, with sinusoidally varying values in between these latitudes; vertically, diffusivity increases to $1.1 \times 10^{-4} \mathrm{~m}^{2} \mathrm{~s}^{-1}$ at a depth of $6150 \mathrm{~m}$ as per Bryan and Lewis (1979). A 7th-order monotonicity-preserving advection scheme (Daru and Tenaud, 2004) is employed and there is no explicit horizontal diffusivity. Horizontal viscosity follows Leith (1996) but is modified to sense the divergent flow (Fox-Kemper and Menemenlis, 2008). The global ocean model is coupled to a sea ice model in a configuration similar to the case C-LSR-ns (see Table 1 in Section 4). The values of open water, dry ice, wet ice, dry snow, and wet snow albedos are, respectively, 0.15, 0.88, 0.79, 0.97, and 0.83 . These values are relatively high compared to observations and they were chosen to compensate for deficiencies in the surface boundary conditions and to produce realistic sea ice extent (Figure 1). 

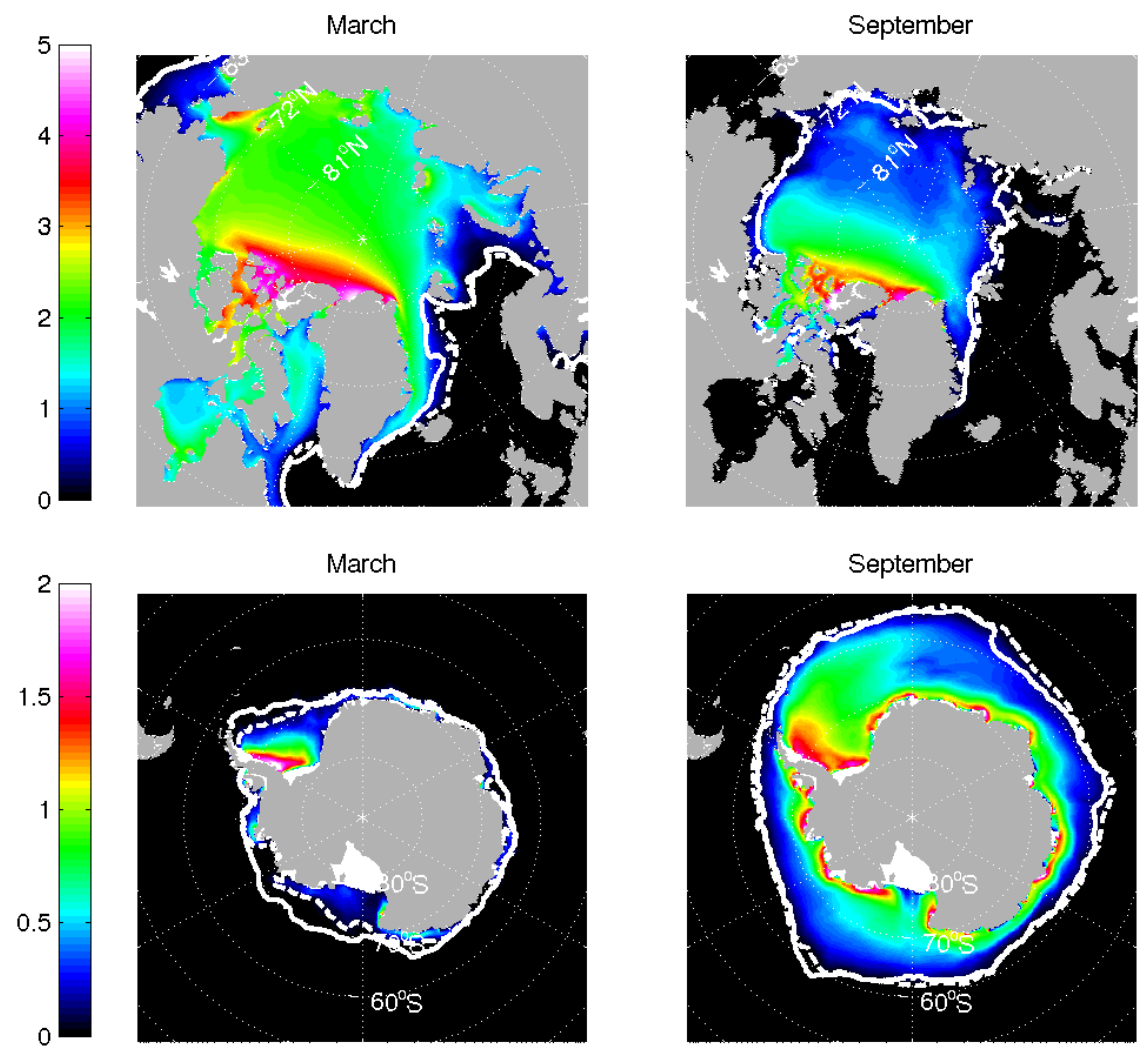

Fig. 1. Effective sea ice thickness distribution (color, in meters) averaged over the years 1992-2002 from an eddy-admitting, global ocean and sea ice simulation. The ice edge estimated as the $15 \%$ isoline of modeled ice concentration is drawn as a white dashed line. The white solid line marks the ice edge, defined as the $15 \%$ isoline of ice concentrations, retrieved from passive microwave satellite data for comparison. The top row shows the results for the Arctic Ocean and the bottom row for the Southern Ocean; the left column shows distributions for March and the right column for September.

The simulation is initialized in January 1979 from rest and from temperature and salinity fields derived from the Polar Science Center Hydrographic Climatology (PHC) 3.0 (Steele et al., 2001). Surface boundary conditions are derived from the European Centre for Medium-Range Weather Forecasts (ECMWF) 40 year re-analysis (ERA-40) (Uppala et al., 2005). Six-hourly surface winds, temperature, humidity, downward short- and long-wave radiation, and precipitation are converted to heat, freshwater, and wind stress fluxes using the Large and Yeager (2004) bulk formulae. Shortwave radiation decays exponentially with depth as per Paulson and Simpson (1977). Low frequency precipitation 
has been adjusted using the pentad (5-day) data from the Global Precipitation Climatology Project (GPCP, Huffman et al., 2001). The time-mean river run-off from Large and Nurser (2001) is applied globally, except in the Arctic Ocean where monthly mean river runoff based on the Arctic Runoff Data Base (ARDB) and prepared by P. Winsor (personal communication, 2007) is specified.

The remainder of this article discusses results from forward sensitivity experiments in a regional Arctic Ocean model, which operates on a sub-domain of, and which obtains open boundary conditions from, the cube76 simulation just described.

\section{Arctic Ocean Sensitivity Experiments}

This section presents results from regional coupled ocean and sea ice simulations of the Arctic Ocean that exercise various capabilities of the MITgcm sea ice model. The objective is to compare the old B-grid LSOR dynamic solver with the new C-grid LSOR and EVP solvers. Additional experiments are carried out to illustrate the differences between different lateral boundary conditions, ice advection schemes, ocean-ice stress formulations, and alternate sea ice thermodynamics.

The Arctic Ocean domain has 420 by 384 grid boxes and is illustrated in Figure 2. For each sensitivity experiment, the model is integrated from January 1 , 1992 to March 31, 2000. This time period is arbitrary and for comparison purposes only: it was chosen to be long enough to observe systematic differences due to details of the model configuration and short enough to allow many sensitivity experiments.

Table 1 gives an overview of all the experiments discussed in this section. In all experiments except for DST3FL ice is advected with the original second order central differences scheme that requires small extra diffusion for stability reasons. The differences between integrations B-LSR-ns and C-LSR-ns can be interpreted as being caused by model finite dimensional numerical truncation.

Both the LSOR and the EVP solvers aim to solve for the same viscous-plastic rheology; while the LSOR solver is an iterative scheme with a convergence criterion the EVP solution relaxes towards the VP solution in the limit of infinite intergration time. The differences between integrations C-LSR-ns, CEVP-10, and C-EVP-03 are caused by fundamentally different approaches to regularize large bulk and shear viscosities; LSOR and other iterative techniques need to clip large viscosities, while EVP introduces elastic waves that damp out within one sub-cycling sequence. Both LSOR and EVP solutions 


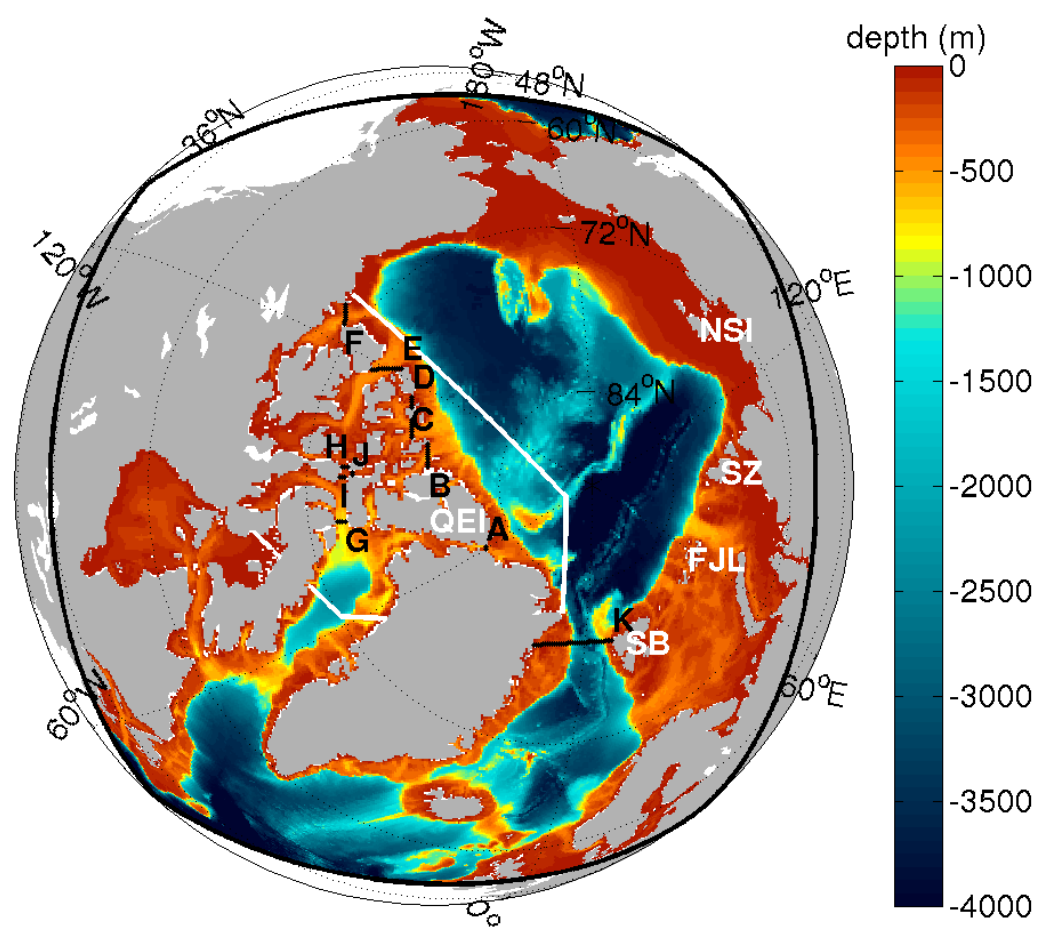

Fig. 2. Bathymetry and domain boundaries of Arctic Domain, cut-out from the global solution. The white line encloses what is loosely referred to as the Canadian Arctic Archipelago in the text. The letters label sections in the Canadian Archipelago, where ice transport is evaluated: A: Nares Strait; B: Peary Channel; C: Prince Gustaf Adolf Sea; D: Ballantyne Strait; E: M'Clure Strait; F: Amundsen Gulf; G: Lancaster Sound; H: Barrow Strait W.; I: Barrow Strait E.; J: Barrow Strait N.; K: Fram Strait. The sections A through F comprise the total Arctic inflow into the Canadian Archipelago. The white labels denote Ellesmere Island of the Queen Elizabeth Islands (QEI), Svalbard (SB), Franz Joseph Land (FJL), Severnaya Zemlya (SZ), and the New Siberian Islands (NSI).

represent approximations to true viscous-plastic rheology and neither will be considered "truth" in our comparisons: On the one hand, LSOR (and other implicit solvers) requires many so-called pseudo time steps to fully converge in a non-linear sense (Lemieux and Tremblay, 2009), which makes this type of solver very expensive. We use only 2 (customary) pseudo time steps. On the other hand, the elastic wave energy in EVP damps out completely only after an infinite time compared to the damping time scale, so that in practice the rheology is not completely viscous-plastic.

For the EVP solver we use two different damping time scales and sub-cycling time steps. In the C-EVP-10 experiment, the damping time scale is one third of the ocean model times step; the EVP model is sub-cycled 120 times within each $1200 \mathrm{~s}$ ocean model time step resulting in $\Delta t_{\text {evp }}=10 \mathrm{~s}$. In the C-EVP-03 experiment, we reduce the damping time scale to a tenth of the ocean model 
Table 1

Overview of forward model sensitivity experiments in a regional Arctic Ocean domain.

\begin{tabular}{|c|c|}
\hline Experiment & Description \\
\hline C-LSR-ns & $\begin{array}{l}\text { The LSOR solver discretized on a } \mathrm{C} \text { grid with no-slip lateral } \\
\text { boundary conditions (implemented via ghost-points), advection } \\
\text { of ice variables with a 2nd-order central difference scheme plus } \\
\text { explicit diffusion for stability. }\end{array}$ \\
\hline B-LSR-ns & $\begin{array}{l}\text { The original LSOR solver of Zhang and Hibler (1997) on an } \\
\text { Arakawa B grid, implying no-slip lateral boundary conditions } \\
\text { ( } \mathbf{u}=0 \text { exactly). }\end{array}$ \\
\hline C-EVP-10 & $\begin{array}{l}\text { The EVP solver of Hunke (2001) on a C grid with no-slip lateral } \\
\text { boundary conditions and } \Delta t_{\text {evp }}=10 \mathrm{~s} \text { ( } \hat{=} 120 \text { subcycling steps). }\end{array}$ \\
\hline C-EVP-03 & $\begin{array}{l}\text { The EVP solver of Hunke (2001) on a C grid with no-slip lateral } \\
\text { boundary conditions and } \Delta t_{\text {evp }}=3 \mathrm{~s} \text { ( } \widehat{=} 400 \text { subcycling steps). }\end{array}$ \\
\hline C-LSR-fs & $\begin{array}{l}\text { The LSOR solver on a } \mathrm{C} \text { grid with free-slip lateral boundary } \\
\text { conditions (no lateral stress on coast lines). }\end{array}$ \\
\hline DST3FL & $\begin{array}{l}\text { C-LSR-ns with a third-order flux limited direct-space-time ad- } \\
\text { vection scheme for thermodynamic variables (Hundsdorfer and } \\
\text { Trompert, 1994). }\end{array}$ \\
\hline TEM & $\begin{array}{l}\text { C-LSR-ns with a truncated ellipse method (TEM) rheology (Hi- } \\
\text { bler and Schulson, 1997). }\end{array}$ \\
\hline HB87 & $\begin{array}{l}\text { C-LSR-ns with ocean-ice stress coupling according to Hibler and } \\
\text { Bryan (1987). }\end{array}$ \\
\hline WTD & $\begin{array}{l}\text { C-LSR-ns with 3-layer thermodynamics following Winton } \\
\text { (2000). }\end{array}$ \\
\hline
\end{tabular}

time step to achieve faster damping of elastic waves. In this case, the EVP model is sub-cycled 400 times within an ocean model time step with a time step of 3 seconds in order to resolve the shorter damping time scale. Table 2 shows timings for these cases. Note that in our configuration on 36 CPUs of a SGI Altix 3700 the EVP technique is faster than LSOR for the 10 seconds time step (C-EVP-10); the shorter time step of 3 seconds was chosen to arrive at approximately the same computational effort as for C-LSR-ns. For comparison purposes, Hunke (2001) used a sub-cycling time step of $30 \mathrm{~s}$ for an ocean model time step of $3600 \mathrm{~s}$ and a damping time scale of $1296 \mathrm{~s}$.

Lateral boundary conditions on a coarse grid (coarse compared to the roughness of the true coast line) are ill-defined so that comparing a no-slip solution (C-LSR-ns) to a free-slip solution (C-LSR-fs) gives another measure of uncertainty in the sea ice model. The sensitivity experiments also explore the response of the coupled ocean and sea ice model to different numerics and 
Table 2

Integration throughput on 36 CPUs of a SGI Altix 3700.

Wall clock per integration month (2232 time steps)

\begin{tabular}{lll} 
Experiment & ice dynamics & entire model \\
\hline C-LSR-ns & $600 \mathrm{sec}$ & $2887 \mathrm{sec}$ \\
C-EVP-10 & $262 \mathrm{sec}$ & $2541 \mathrm{sec}$ \\
C-EVP-03 & $875 \mathrm{sec}$ & $3159 \mathrm{sec}$
\end{tabular}

physics, that is, to changes in advection and diffusion properties (DST3FL), in rheology (TEM), in stress coupling (HB87), and in thermodynamics (WTD).

Comparing the solutions obtained with different realizations of the model dynamics is difficult because of the non-linear feedback of the ice dynamics and thermodynamics. Already after a few months the model trajectories have diverged far enough so that velocity differences are easier to interpret within the first 3 months of the integration while the ice distributions are still comparable. The effect on ice-thickness of different numerics tends to accumulate along the time integration, resulting in larger differences - also easier to interpret at the end of the integration. We choose C-LSR-ns as the reference run for all comparisons bearing in mind that any other choice is equally valid.

Tables 3 and 4 summarize the differences in drift speed and effective ice thickness for all experiments. These differences are discussed in detail below.

\subsection{Ice velocities in JFM 1992}

Figure 3 shows ice velocities averaged over January, February, and March (JFM) of 1992 for the C-LSR-ns solution; also shown are the differences between this reference solution and various sensitivity experiments. The velocity field of the C-LSR-ns solution (Figure 3a) roughly resembles the drift velocities of some of the AOMIP (Arctic Ocean Model Intercomparison Project) models in a cyclonic circulation regime (Martin and Gerdes, 2007, their Figure 6) with a Beaufort Gyre and a Transpolar Drift shifted eastwards towards Alaska.

The difference between experiments C-LSR-ns and B-LSR-ns (Figure 3b) is most pronounced $(\sim 2 \mathrm{~cm} / \mathrm{s})$ along the coastlines, where the discretization differs most between $\mathrm{B}$ and $\mathrm{C}$ grids. On a $\mathrm{B}$ grid the tangential velocity lies on the boundary, and is thus zero through the no-slip boundary conditions, whereas on the $\mathrm{C}$ grid it is half a cell width away from the boundary, thus allowing more flow. The B-LSR-ns solution has less ice drift through the Fram Strait and along Greenland's East Coast; also, the flow through Baffin Bay and 
Table 3

Overview over drift speed differences (JFM of first year of integration) and effective ice thickness differences (JFM of last year of integration) relative to C-LSR-ns. For reference the corresponding values for C-LSR-ns are given in the first line.

\begin{tabular}{lrrrr} 
speed $(\mathrm{cm} / \mathrm{s})$ & & & & \\
& mean & rms & median & $\max$ \\
\hline C-LSR-ns (ref) & 3.295 & 4.711 & 2.502 & 28.599 \\
\hline B-LSR-ns & -0.236 & 0.714 & -0.071 & 14.355 \\
C-EVP-10 & 0.266 & 0.513 & 0.213 & 10.506 \\
C-EVP-03 & 0.198 & 0.470 & 0.143 & 10.407 \\
C-LSR-fs & 0.160 & 0.472 & 0.084 & 9.921 \\
DST3FL & 0.035 & 0.301 & 0.008 & 10.251 \\
TEM & 0.027 & 0.168 & 0.014 & 8.922 \\
HB87 & 0.184 & 0.316 & 0.169 & 9.175 \\
WTD & 0.354 & 1.418 & 0.039 & 26.298
\end{tabular}

thickness (m)

\begin{tabular}{lrrrr} 
& mean & rms & median & $\max$ \\
\hline C-LSR-ns (ref) & 1.599 & 1.941 & 1.542 & 10.000 \\
\hline B-LSR-ns & 0.065 & 0.175 & 0.049 & 2.423 \\
C-EVP-10 & -0.082 & 0.399 & -0.020 & 5.993 \\
C-EVP-03 & -0.069 & 0.374 & -0.014 & 5.688 \\
C-LSR-fs & -0.037 & 0.289 & -0.005 & 3.947 \\
DST3FL & 0.014 & 0.338 & -0.018 & 9.246 \\
TEM & -0.020 & 0.138 & -0.001 & 2.541 \\
HB87 & -0.052 & 0.114 & -0.029 & 2.520 \\
WTD & 0.518 & 0.667 & 0.528 & 4.144
\end{tabular}

Davis Strait into the Labrador Sea is reduced with respect to the C-LSR-ns solution.

The C-EVP-10 solution with $\Delta t_{\text {evp }}=10 \mathrm{~s}$ allows for increased drift by order $1 \mathrm{~cm} / \mathrm{s}$ in the Beaufort Gyre and in the Transpolar Drift. In general, drift velocities tend towards higher values in the EVP solution with a root-meansquare (rms) difference of $0.51 \mathrm{~cm} / \mathrm{s}$. As the number of sub-cycling time steps increases, the EVP approximation converges towards VP dynamics: the C- 
Table 4

Root-mean-square differences for drift speed (JFM of first year of integration) and effective thickness (JFM of last year of integration) for the "Candian Arctic Archipelago" defined in Figure 2 and the remaining domain ("rest"). For reference the corresponding values for C-LSR-ns are given in the first line.

\begin{tabular}{lrrrrrr} 
& \multicolumn{3}{c}{ rms(speed) } & $(\mathrm{cm} / \mathrm{s})$ & \multicolumn{3}{c}{ rms(thickness) $(\mathrm{m})$} \\
& total & CAA & rest & total & CAA & rest \\
\hline C-LSR-ns (ref) & 4.711 & 1.425 & 5.037 & 1.941 & 3.304 & 1.625 \\
\hline B-LSR-ns & 0.714 & 0.445 & 0.747 & 0.175 & 0.369 & 0.117 \\
C-EVP-10 & 0.513 & 0.259 & 0.543 & 0.399 & 1.044 & 0.105 \\
C-EVP-03 & 0.470 & 0.234 & 0.497 & 0.374 & 0.982 & 0.095 \\
C-LSR-fs & 0.472 & 0.266 & 0.497 & 0.289 & 0.741 & 0.099 \\
DST3FL & 0.301 & 0.063 & 0.323 & 0.338 & 0.763 & 0.201 \\
TEM & 0.168 & 0.066 & 0.179 & 0.138 & 0.359 & 0.040 \\
HB87 & 0.316 & 0.114 & 0.337 & 0.114 & 0.236 & 0.079 \\
WTD & 1.418 & 1.496 & 1.406 & 0.667 & 1.110 & 0.566
\end{tabular}

EVP-03 solution with $\Delta t_{\text {evp }}=3 \mathrm{~s}$ (Figure $3 \mathrm{~d}$ ) is closer to the C-LSR-ns solution (root-mean-square of $0.47 \mathrm{~cm} / \mathrm{s}$ and only $0.23 \mathrm{~cm} / \mathrm{s}$ in the CAA). Both EVP solutions have a stronger Beaufort Gyre as in Hunke and Zhang (1999).

As expected the differences between C-LSR-fs and C-LSR-ns (Figure 3e) are also largest $(\sim 2 \mathrm{~cm} / \mathrm{s})$ along the coastlines. The free-slip boundary condition of C-LSR-fs allows the flow to be faster, for example, along the East Coast of Greenland, the North Coast of Alaska, and the East Coast of Baffin Island, so that the ice drift for C-LSR-fs is on average faster than for C-LSR-ns where for B-LSR-ns it is on average slower.

The more sophisticated advection scheme of DST3FL (Figure 3f) has the largest effect along the ice edge (see also Merryfield and Holloway, 2003), where the gradients of thickness and concentration are largest and differences in velocity can reach $5 \mathrm{~cm} / \mathrm{s}$ (maximum differences are $10 \mathrm{~cm} / \mathrm{s}$ at individual grid points). Everywhere else the effect is very small $(\mathrm{rms}$ of $0.3 \mathrm{~cm} / \mathrm{s})$ and can mostly be attributed to smaller numerical diffusion (and to the absence of explicit diffusion that is required for numerical stability in a simple second order central differences scheme). Note, that the advection scheme has an indirect effect on the ice drift, but a direct effect on the ice transport, and hence the ice thickness distribution and ice strength; a modified ice strength then leads to a modified drift field.

Compared to the other parameters, the ice rheology TEM (Figure 3g) also has 


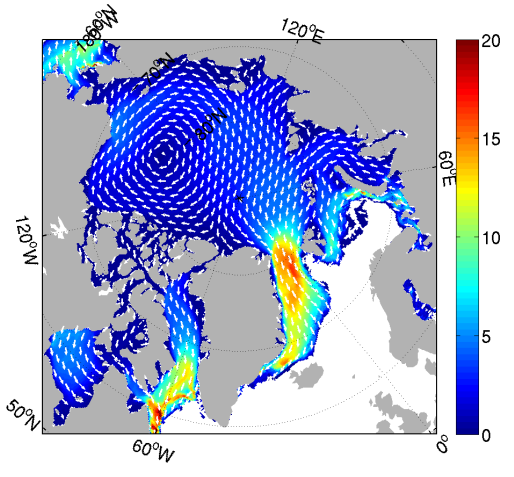

(a) C-LSR-ns

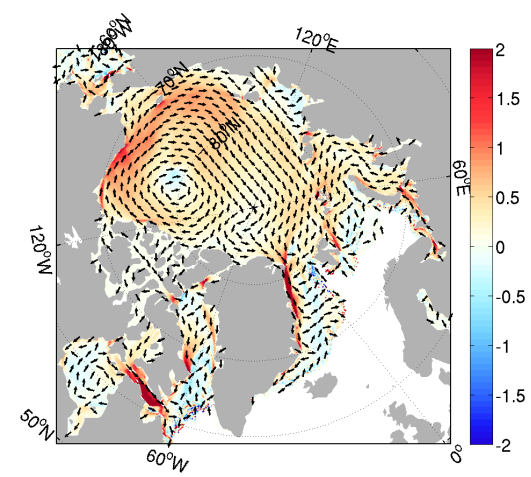

(c) C-EVP-10 - C-LSR-ns

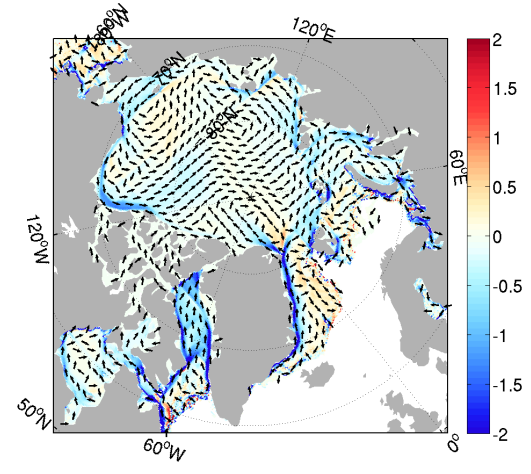

(b) B-LSR-ns - C-LSR-ns

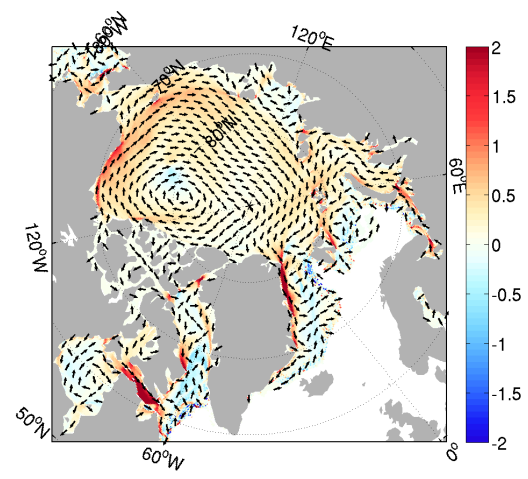

(d) C-EVP-03 - C-LSR-ns

Fig. 3. (a) Ice drift velocity of the C-LSR-ns solution averaged over the first 3 months of integration $(\mathrm{cm} / \mathrm{s})$; (b)-(h) difference between the C-LSR-ns reference solution and solutions with, respectively, the B-grid solver, the EVP-solver with $\Delta t_{\mathrm{evp}}=10 \mathrm{~s}$, the EVP-solver with $\Delta t_{\mathrm{evp}}=3 \mathrm{~s}$, free lateral slip, a different advection scheme (DST3FL) for thermodynamic variables, the truncated ellipse method (TEM), and a different ice-ocean stress formulation (HB87). Color indicates speed or differences of speed and vectors indicate direction only. The direction vectors represent block averages over eight by eight grid points at every eighth velocity point. Note that color scale varies from panel to panel.

a very small (mostly $<0.5 \mathrm{~cm} / \mathrm{s}$ and the smallest rms-difference of all solutions) effect on the solution. In general the ice drift tends to increase because there is no tensile stress and ice can drift apart at no cost. Consequently, the largest effect on drift velocity can be observed near the ice edge in the Labrador Sea. Note in experiments DST3FL and TEM the drift pattern is slightly changed as opposed to all other C-grid experiments, although this change is small.

By way of contrast, the ice-ocean stress formulation of Hibler and Bryan (1987) results in stronger drift by up to $2 \mathrm{~cm} / \mathrm{s}$ almost everywhere in the computational domain (Figure 3h). The increase is mostly aligned with the general direction of the flow, implying that the Hibler and Bryan (1987) stress formulation reduces the deceleration of drift by the ocean. 


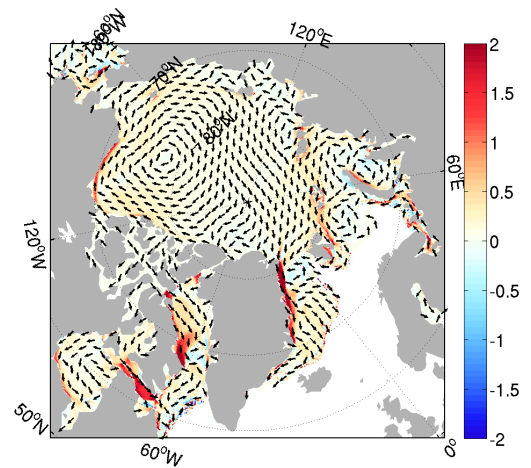

(e) C-LSR-fs - C-LSR-ns

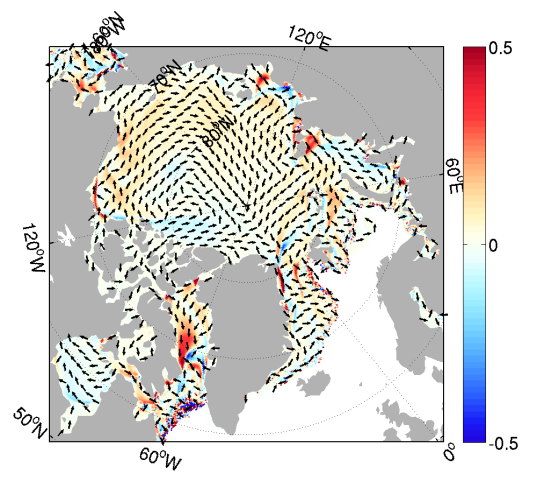

(g) TEM - C-LSR-ns

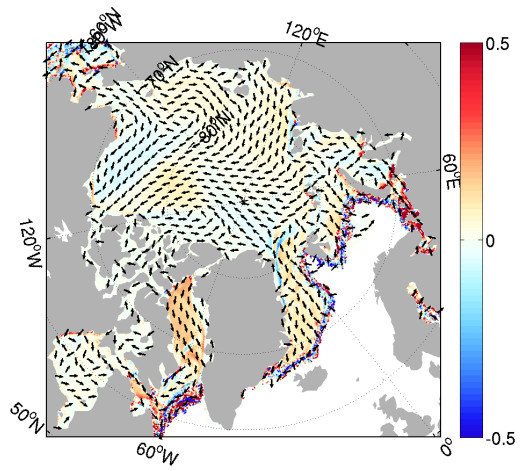

(f) DST3FL - C-LSR-ns

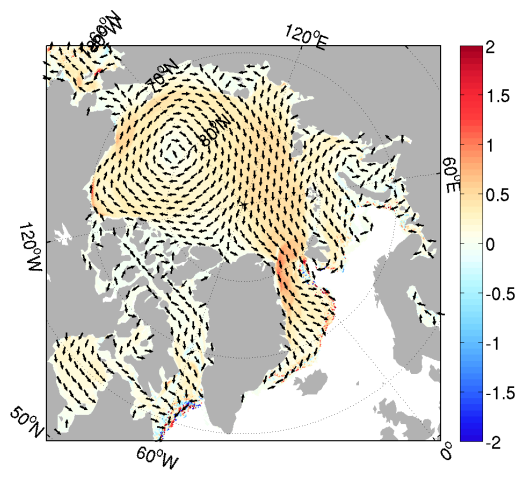

(h) HB87 - C-LSR-ns

Fig. 3. Continued.

\subsection{Integrated effect on ice volume during JFM 2000}

Figure 4a shows the effective thickness (volume per unit area) of the C-LSR-ns solution, averaged over January, February, and March of year 2000, that is, eight years after the start of the simulation. By this time of the integration, the differences in ice drift velocities have led to the evolution of very different ice thickness distributions (as shown in Figs. 4b-h) and concentrations (not shown) for each sensitivity experiment. The mean ice volume for the JanuaryMarch 2000 period is also reported in Table 5.

The generally weaker ice drift velocities in the B-LSR-ns solution, when compared to the C-LSR-ns solution, in particular through the narrow passages in the Canadian Arctic Archipelago, where the B-LSR-ns solution tends to block channels more often than the C-LSR-ns solution, lead to a larger build-up of ice (2 $\mathrm{m}$ or more) north of Greenland and north of the Archipelago in the Bgrid solution (Figure 4b). The ice volume, however, is not larger everywhere. Further west there are patches of smaller ice volume in the B-grid solution, most likely because the Beaufort Gyre is weaker and hence not as effective in transporting ice westwards. There is no obvious explanation, why the ice is 


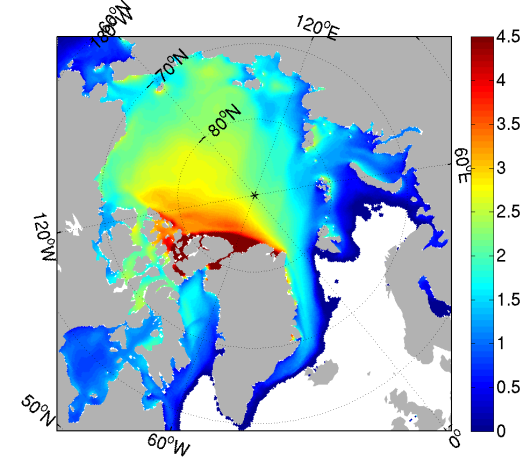

(a) C-LSR-ns

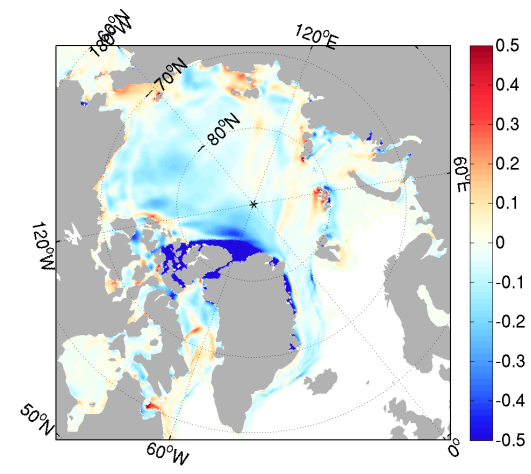

(c) C-EVP-10 - C-LSR-ns

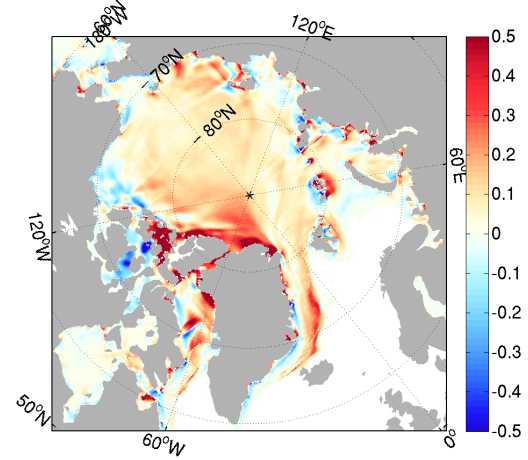

(b) B-LSR-ns - C-LSR-ns

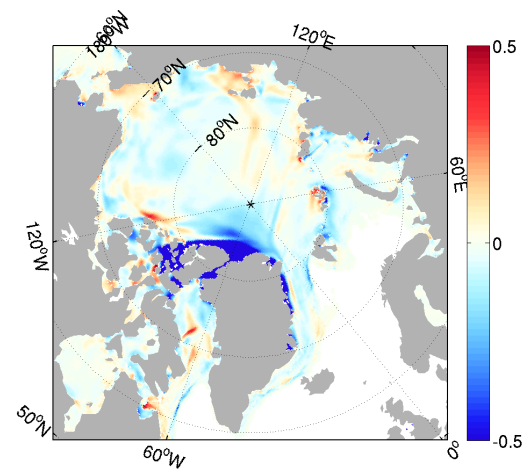

(d) C-EVP-03 - C-LSR-ns

Fig. 4. (a) Effective thickness (volume per unit area) of the C-LSR-ns solution, averaged over the months January through March 2000 (m); (b)-(h) difference between the C-LSR-ns reference solution and solutions with, respectively, the B-grid solver, the EVP-solver with $\Delta t_{\text {evp }}=10 \mathrm{~s}$, the EVP-solver with $\Delta t_{\text {evp }}=3 \mathrm{~s}$, free lateral slip, a different advection scheme (DST3FL) for thermodynamic variables, the truncated ellipse method (TEM), and a different ice-ocean stress formulation (m).

thinner in the western part of the Canadian Archipelago. We attribute this difference to the different effective slipperiness of the coastlines in the two solutions, because in the free-slip solution the pattern is reversed. There are also dipoles of ice volume differences with more ice on the upstream side and less ice on the downstream side of island groups, for example, of Franz Josef Land, of Severnaya Zemlya, of the New Siberian Islands, and of the Queen Elizabeth Islands (see Figure 2 for their geographical locations). This is because ice tends to flow less easily along coastlines, around islands, and through narrow channels in the B-LSR-ns solution than in the C-LSR-ns solution.

The C-EVP-10 solution with $\Delta t_{\mathrm{evp}}=10 \mathrm{~s}$ has thinner ice in the Candian Archipelago and in the central Arctic Ocean than the C-LSR-ns solution (Figure 4c); the rms difference between C-EVP-10 and C-LSR-ns ice thickness is $40 \mathrm{~cm}$. Thus it is larger than the rms difference between B- and CLSR-ns, mainly because within the Canadian Arctic Archipelago more drift 


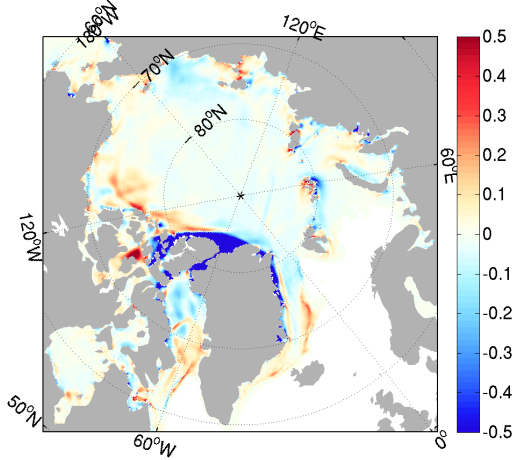

(e) C-LSR-fs - C-LSR-ns

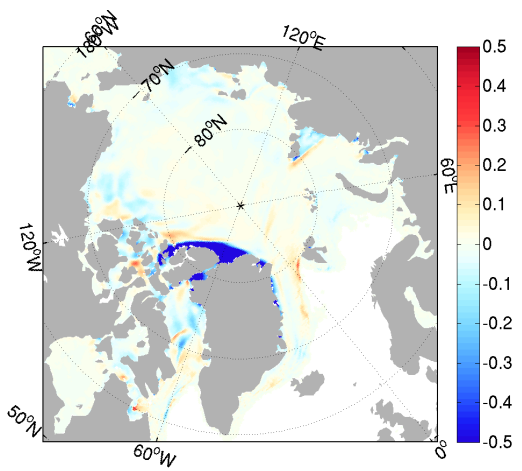

(g) TEM - C-LSR-ns

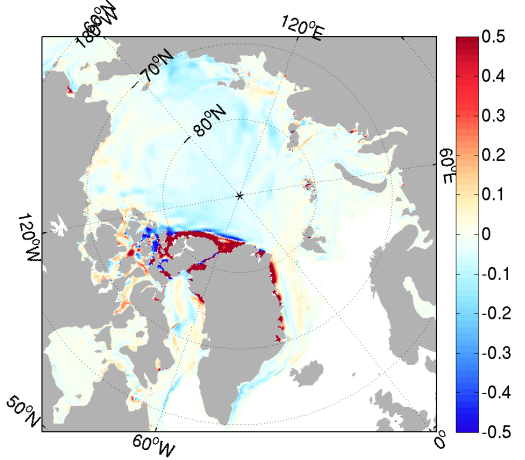

(f) DST3FL - C-LSR-ns

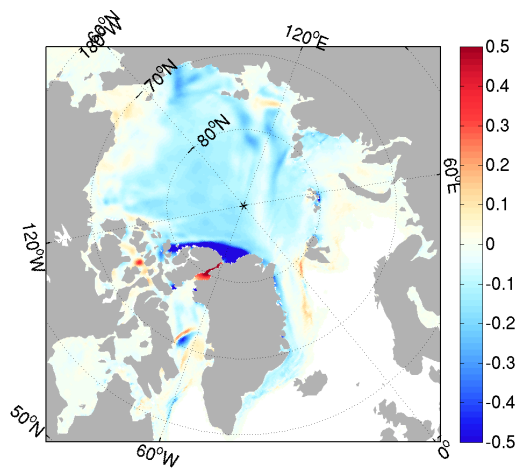

(h) HB87 - C-LSR-ns

Fig. 4. Continued.

Table 5

Arctic ice volume averaged over Jan-Mar 2000, in $\mathrm{km}^{3}$. Mean ice transport (and standard deviation in parenthesis) for the period Jan 1992 - Dec 1999 through the Fram Strait (FS), the total northern inflow into the Canadian Arctic Archipelago (CAA), and the export through Lancaster Sound (LS), in $\mathrm{km}^{3} \mathrm{y}^{-1}$.

Volume Sea ice transport $\left(\mathrm{km}^{3} \mathrm{yr}^{-1}\right)$

\begin{tabular}{lllll} 
Experiment & $\left(\mathrm{km}^{3}\right)$ & FS & CAA & LS \\
\hline C-LSR-ns & 24,769 & $2196(1253)$ & $70(224)$ & $77(110)$ \\
B-LSR-ns & 23,824 & $2126(1278)$ & $34(122)$ & $43(76)$ \\
C-EVP-10 & 22,633 & $2174(1260)$ & $186(496)$ & $133(128)$ \\
C-EVP-03 & 22,819 & $2161(1252)$ & $175(461)$ & $123(121)$ \\
C-LSR-fs & 23,286 & $2236(1289)$ & $80(276)$ & $91(85)$ \\
DST3FL & 24,023 & $2191(1261)$ & $88(251)$ & $84(129)$ \\
TEM & 23,529 & $2222(1258)$ & $60(242)$ & $87(112)$ \\
HB87 & 23,060 & $2256(1327)$ & $64(230)$ & $77(114)$ \\
WTD & 31,634 & $2761(1563)$ & $23(140)$ & $94(63)$
\end{tabular}


in C-EVP-10 leads to faster ice export and to reduced effective ice thickness. With a shorter time step $\left(\Delta t_{\text {evp }}=3 \mathrm{~s}\right)$ the EVP solution converges towards the LSOR solution in the central Arctic (Figure 4d). In the narrow straits in the Archipelago, however, the ice thickness is not affected by the shorter time step and the ice is still thinner by $2 \mathrm{~m}$ or more, as it is in the EVP solution with $\Delta t_{\mathrm{evp}}=10 \mathrm{~s}$.

Imposing a free-slip boundary condition in C-LSR-fs leads to much smaller differences to C-LSR-ns (Figure 4e) than the transition from the B grid to the C grid, except in the Canadian Arctic Archipelago, where the free-slip solution allows more flow (see Table 4). There, it reduces the effective ice thickness by $2 \mathrm{~m}$ or more where the ice is thick and the straits are narrow (leading to an overall larger rms-difference than the B-LSR-ns solution, see Table 4). Dipoles of ice thickness differences can also be observed around islands because the free-slip solution allows more flow around islands than the no-slip solution. The differences in the Central Arctic are much smaller in absolute value than the differences in the Canadian Arctic Archipelago although there are also interesting changes in the ice-distribution in the interior: Less ice in the Central Arctic is most likely caused by more export (see Table 5).

The remaining sensitivity experiments, DST3FL, TEM, and HB87, have the largest differences in effective ice thickness along the north coasts of Greenland and Ellesmere Island in the Canadian Arctic Archipelago. Although using the TEM rheology and the Hibler and Bryan (1987) ice-ocean stress formulation has different effects on the initial ice velocities (Figure $3 \mathrm{~g}$ and $\mathrm{h}$ ), both experiments have similarly reduced ice thicknesses in this area. The 3rd-order advection scheme (DST3FL) has an opposite effect of similar magnitude, pointing towards more implicit lateral stress with this numerical scheme. The HB87 experiment shows ice thickness reduction in the entire Arctic basin greater than in any other experiment, possibly because more drift leads to faster export of ice.

Figure 5 summarizes Figures 3 and 4 by showing histograms of sea ice thickness and drift velocity differences to the reference C-LSR-ns. The black line is the cumulative number grid points in percent of all grid points of all models where differences up to the value on the abscissa are found. For example, ice thickness differences up to $50 \mathrm{~cm}$ are found in $90 \%$ of all grid points, or equally differences above $50 \mathrm{~cm}$ are only found in $10 \%$ of all grid points. The colors indicate the distribution of these grid points between the various experiments. For example, $65 \%$ to $90 \%$ of grid points with ice thickness differences between $40 \mathrm{~cm}$ and $1 \mathrm{~m}$ are found in the run WTD. The runs B-LSR-ns, C-EVP-10, and HB87 only have a fairly large number of grid points with differences below $40 \mathrm{~cm}$. B-LSR-ns and WTD dominate nearly all velocity differences. The remaining contributions are small except for small differences below $1 \mathrm{~cm} / \mathrm{s}$. Only very few points contribute to very large differences in thickness (above $1 \mathrm{~m}$ ) and 


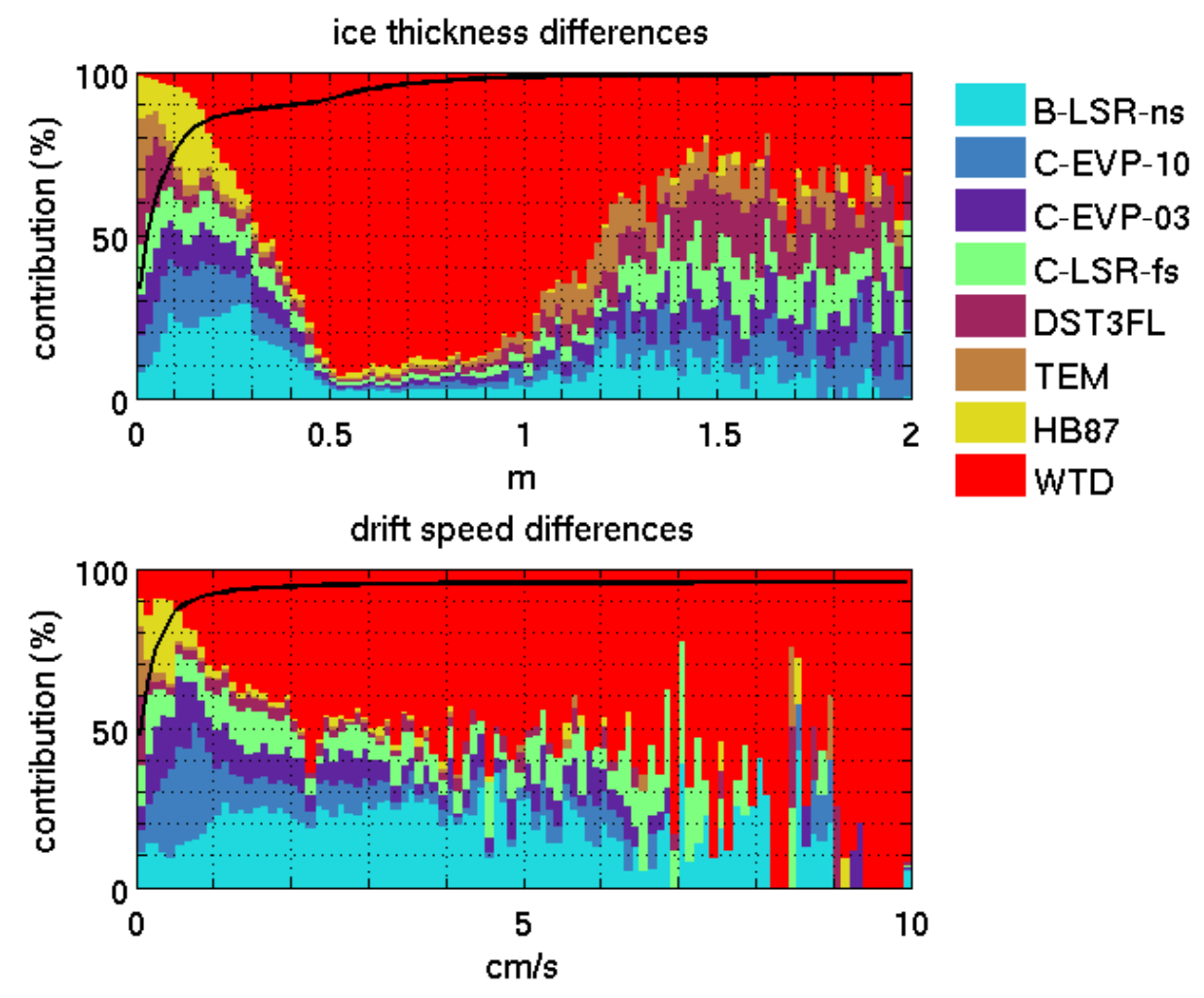

Fig. 5. Histograms of ice thickness and drift velocity differences relative to C-LSR-ns; the bin-width is $2 \mathrm{~cm}$ for thickness and $0.1 \mathrm{~cm} / \mathrm{s}$ for speed. The black line is the cumulative number of grid points in percent of all grid points. The colors indicate the distribution of these grid points between the various experiments in percent of the black line.

velocity (above $4 \mathrm{~cm} / \mathrm{s}$ ) indicated by the small slope of the cumlative number of grid point (black line).

\subsection{Ice transports}

The difference in ice volume and in ice drift velocity between the various sensitivity experiments has consequences for sea ice export from the Arctic Ocean. As an illustration (other years are similar), Figure 6 shows the 1996 time series of sea ice transports through the northern edge of the Canadian Arctic Archipelago, through Lancaster Sound, and through Fram Strait for each model sensitivity experiment. The mean and standard deviation of these ice transports, over the period January 1992 to December 1999, are reported in Table 5. In addition to sea ice dynamics, there are many factors, e.g., atmospheric and oceanic forcing, drag coefficients, and ice strength, that control sea ice export. Although calibrating these various factors is beyond the scope of this manuscript, it is nevertheless instructive to compare the values in Table 5 with published estimates, as is done next. This is a necessary step towards con- 

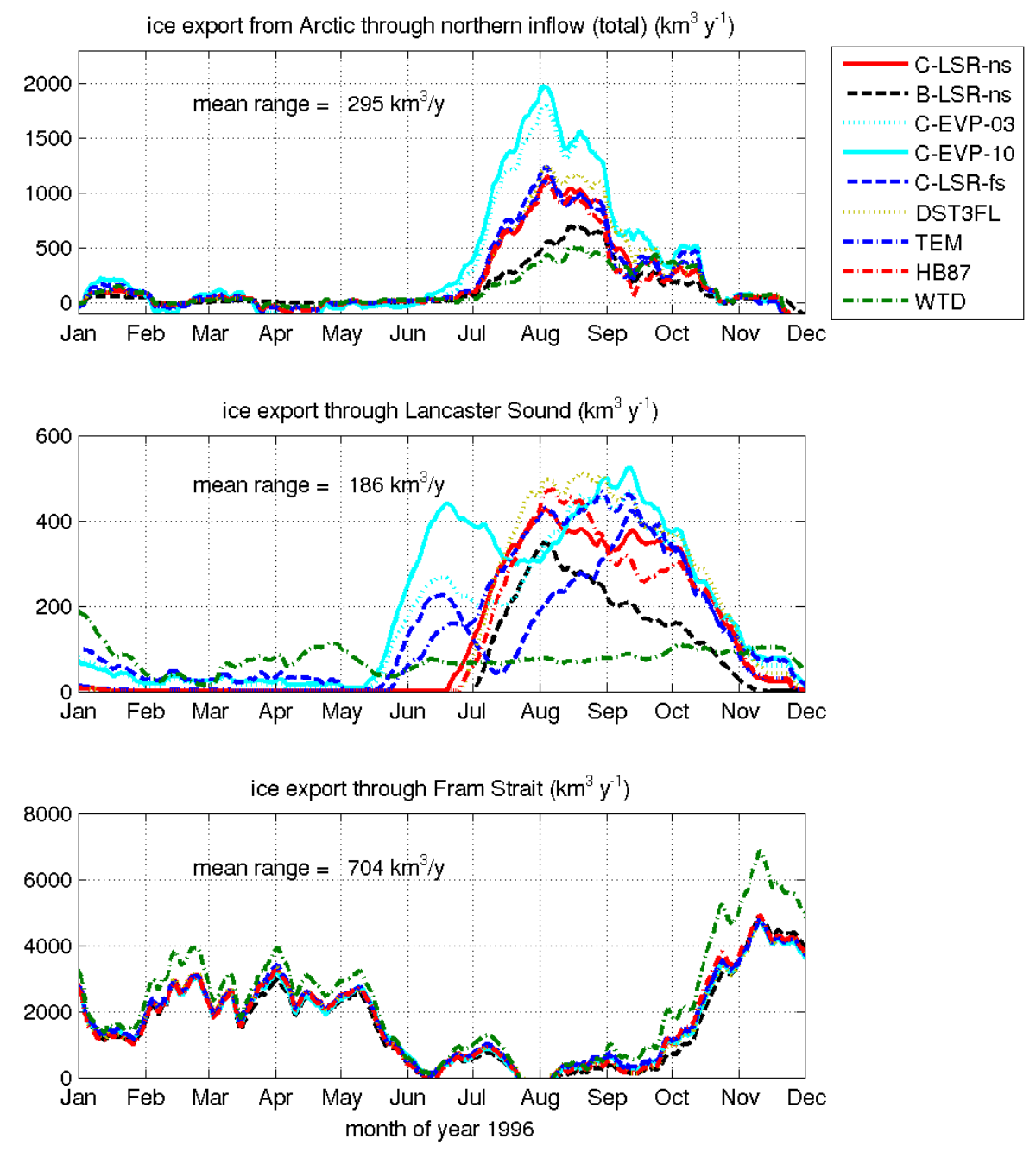

Fig. 6. Transports of sea ice during 1996 for model sensitivity experiments listed in Table 1. Top panel shows flow through the northern edge of the Canadian Arctic Archipelago (Sections A-F in Figure 2), middle panel shows flow through Lancaster Sound (Section G), and bottom panel shows flow through Fram Strait (Section K). Positive values indicate sea ice flux out of the Arctic Ocean. The time series are smoothed using a monthly running mean. The mean range, i.e., the time-mean difference between the model solution with maximum flux and that with minimum flux, is computed over the period January 1992 to December 1999.

straining this model with data, a key motivation for developing the MITgcm sea ice model and its adjoint.

The export through Fram Strait for all the sensitivity experiments is consistent with the value of $2300 \pm 610 \mathrm{~km}^{3} \mathrm{yr}^{-1}$ reported by Serreze et al. (2006, and references therein). Although Arctic sea ice is exported to the Atlantic Ocean principally through the Fram Strait, Serreze et al. (2006) estimate that a 
considerable amount of sea ice $\left(\sim 160 \mathrm{~km}^{3} \mathrm{yr}^{-1}\right)$ is also exported through the Canadian Arctic Archipelago. This estimate, however, is associated with large uncertainties. For example, Dey (1981) estimates an inflow into Baffin Bay of 370 to $537 \mathrm{~km}^{3} \mathrm{yr}^{-1}$ but a flow of only 102 to $137 \mathrm{~km}^{3} \mathrm{yr}^{-1}$ further upstream in Barrow Strait in the 1970's from satellite images; Aagaard and Carmack (1989) give approximately $155 \mathrm{~km}^{3} \mathrm{yr}^{-1}$ for the export through the CAA. The recent estimates of Agnew et al. (2008) for Lancaster Sound are lower: $102 \mathrm{~km}^{3} \mathrm{yr}^{-1}$. The model results suggest annually averaged ice transports through Lancaster Sound ranging from 43 to $133 \mathrm{~km}^{3} \mathrm{yr}^{-1}$ and total northern inflow of 34 to $186 \mathrm{~km}^{3} \mathrm{yr}^{-1}$ (Table 5). These model estimates and their standard deviations cannot be rejected based on the observational estimates.

Generally, the EVP solutions have the highest maximum (export out of the Arctic) and lowest minimum (import into the Arctic) fluxes as the drift velocities are largest in these solutions. In the extreme of the Nares Strait, which is only a few grid points wide in our configuration, both B- and C-grid LSOR solvers lead to practically no ice transport, while the EVP solutions allow $200-500 \mathrm{~km}^{3} \mathrm{yr}^{-1}$ in summer (not shown). Tang et al. (2004) report 300 to $350 \mathrm{~km}^{3} \mathrm{yr}^{-1}$ and Kwok (2005) $130 \pm 65 \mathrm{~km}^{3} \mathrm{yr}^{-1}$. As as consequence, the import into the Canadian Arctic Archipelago is larger in all EVP solutions than in the LSOR solutions. The B-LSR-ns solution is even smaller by another factor of two than the C-LSR solutions.

\subsection{Thermodynamics}

The last sensitivity experiment (WTD) listed in Table 1 is carried out using the 3-layer thermodynamics model of Winton (2000). This experiment has different albedo and basal heat exchange formulations from all the other experiments. Although, the upper-bound albedo values for dry ice, dry snow, and wet snow are the same as for the zero-layer model, the ice albedos in WTD are computed following Hansen et al. (1983) and can become much smaller as a function of thickness $h$, with a minimum value of $0.2 \exp (-h / 0.44 \mathrm{~m})$. Further the snow age is taken into account when computing the snow albedo. With the same values for wet snow (0.83), dry snow (0.97), and dry ice (0.88) as for the zero-heat-capacity model (see Section 3), this results in albedos that range from 0.22 to 0.95 (not shown). Similarly, large differences can be found in the basal heat exchange parameterizations. For this reason, the resulting ice velocities, volume, and transports have not been included in the earlier comparisons. However, this experiment gives another measure of uncertainty associated with ice modeling. The key difference with the "zero-layer" thermodynamic model is a delay in the seaice cycle of approximately one month in the maximum sea-ice thickness and two months in the minimum sea-ice thickness. This is shown in Figure 7, which compares the mean sea-ice thickness seasonal 


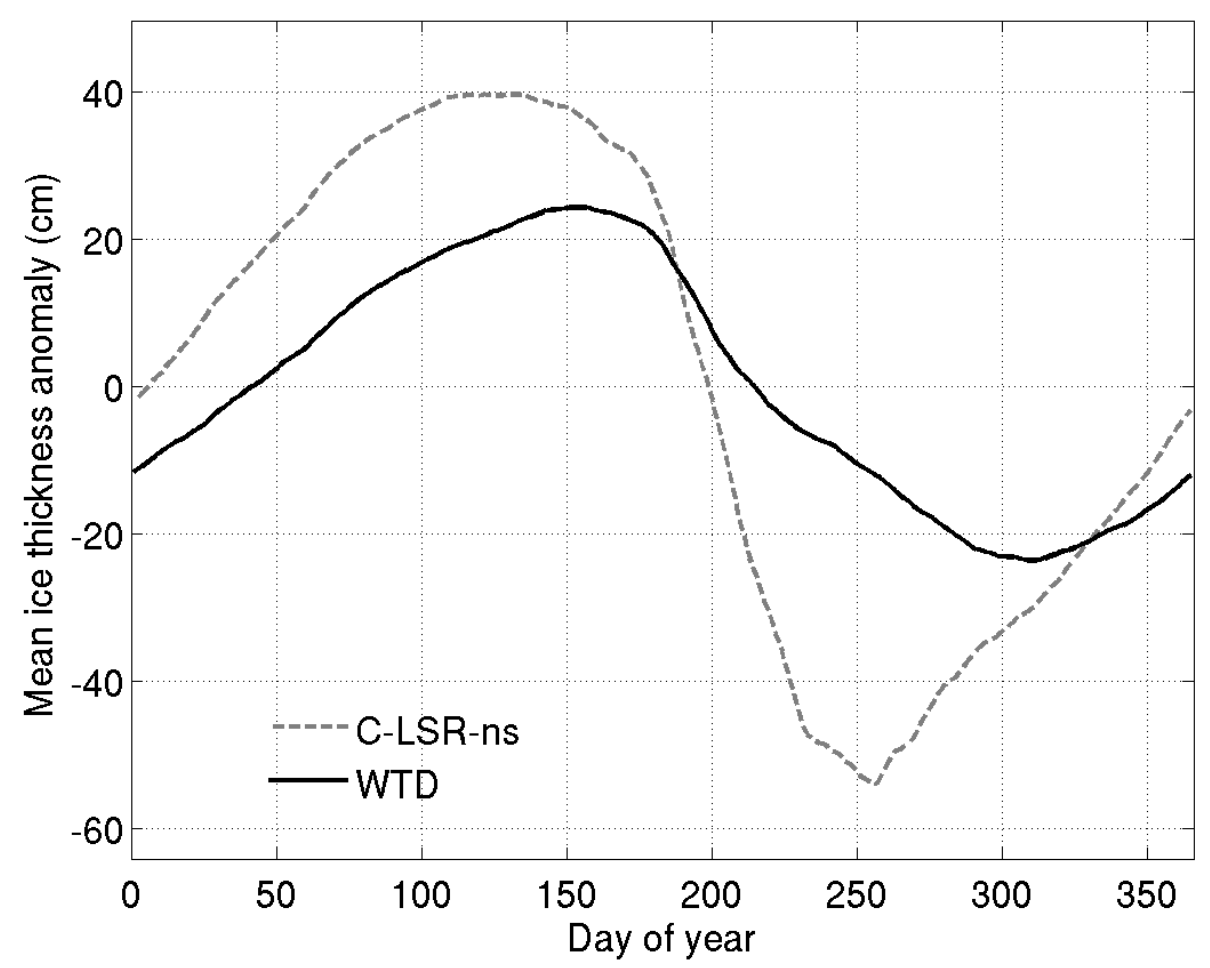

Fig. 7. Seasonal cycle of mean sea-ice thickness $(\mathrm{cm})$ in a sector in the western Arctic $\left(75^{\circ} \mathrm{N}\right.$ to $85^{\circ} \mathrm{N}$ and $180^{\circ} \mathrm{W}$ to $\left.140^{\circ} \mathrm{W}\right)$ averaged over $1992-2000$ of experiments C-LSR-ns and WTD.

cycle of experiments with the zero-heat-capacity (C-LSR-ns) and three-layer (WTD) thermodynamic model. The mean ice thickness is computed for a sector in the western Arctic $\left(75^{\circ} \mathrm{N}\right.$ to $85^{\circ} \mathrm{N}$ and $180^{\circ} \mathrm{W}$ to $\left.140^{\circ} \mathrm{W}\right)$ in order to avoid confounding thickness and extent differences. Similar to Semtner (1976), the seasonal cycle for the "zero-layer" model (gray dashed line) is almost twice as large as for the three-layer thermodynamic model.

\section{Conclusions}

We have shown that changes in discretization details, in boundary conditions, and in sea-ice-dynamics formulation lead to considerable differences in model results. Notably the sea-ice-dynamics formulation, e.g., B-grid versus C-grid or EVP versus LSOR, has as much or even greater influence on the solution than physical parameterizations, e.g., free-slip versus no-slip boundary conditions.

This is especially true

- in regions of convergence (see ice thickness north of Greenland in Fig. 4),

- along coasts (see eastern coast of Greenland in Fig. 3 where velocity differ- 
ences are apparent),

- and in the vicinity of straits (see the Canadian Arctic Archipelago in Figs. 3 and 4).

These experiments demonstrate that sea-ice export from the Arctic into both the Baffin Bay and the GIN (Greenland/Iceland/Norwegian) Sea regions is highly sensitive to numerical formulation. Changes in export in turn impact deep-water mass formation in the northern North Atlantic. Therefore uncertainties due to numerical formulation might potentially have wide reaching impacts outside of the Arctic.

The relatively large differences between solutions with different dynamical solvers is somewhat surprising. The expectation was that the solution technique should not affect the solution to a higher degree than actually modifying the equations. The EVP solutions tend to produce effectively "weaker" ice that yields more easily to stress than the LSOR solutions, similar to the findings in Hunke and Zhang (1999). The differences between LSOR and EVP can, in part, stem from incomplete convergence of the solvers due to linearization and due to different methods of linearization (Hunke, 2001, and B. Tremblay, pers. comm. 2008). We note that the EVP-to-LSOR differences decrease with decreasing sub-cycling time step but that the difference remains significant even at a 3-second sub-cycling period. For the LSOR solutions we use 2 pseudo time steps so that the convergence of the non-linear momentum equations may not be complete. This effect is most likely reduced and constrained to small areas as in Lemieux and Tremblay (2009) because of the small time step that we used. Whether more pseudo time steps make the LSOR solution generate weaker ice requires further investigation. Preliminary tests indicate that the viscosity increases with increasing number of LSOR pseudo time steps, especially in areas of thick ice (not shown).

Other numerical formulation choices that were tested include switching from one horizontal grid staggering (C-grid) to another (B-grid). This change significantly affects narrow straits, for example, in the Canadian Arctic Archipelago, and subsequent conditions upstream and downstream of the straits. It also affects flows of ice along the West Greenland coast. Similar, but smaller, differences between B-grid and C-grid sea ice solutions were noted in the coarserresolution study of Bouillon et al. (2009). The differences between the no-slip and free-slip lateral boundary conditions are also most significant near the coast. As in the case of oceanic boundary conditions (Adcroft and Marshall, 1998), we expect that the changes are due to the effective "slipperiness" of the coastline boundary condition.

The flux-limited scheme without explicit diffusion (DST3FL) is recommended. This is because the flux-limited scheme preserves sharp gradients and edges that are typical of sea ice distributions and because it avoids unphysical (neg- 
ative) values for ice thickness and concentration (see also Merryfield and Holloway, 2003). The flux limited scheme conserves volume and horizontal area and is unconditionally stable, so that no extra diffusion is required.

Changing the ice rheology to the truncated ellipse method (TEM) primarily impacts the solution in the Canadian Arctic Archipelago and the West Greenland coast as does altering the stress formulation on the ice solution. We interpret this result as indicating that the CAA and West Greenland current are regions of high-sensitivity. Here, more ice leads to a rigid structure that inhibits ice flow and yields ice accumulation upstream.

Although the Hibler and Bryan (1987) stress formulation appears more natural for advecting sea ice, the advection of oceanic properties is problematic: Thermodynamic and passive tracers in the top ocean model level are advected with a velocity that is the average over ice drift and ocean currents rather than an average of surface oceanic currents alone. For our purposes, the preferred iceocean coupling uses the rescaled vertical coordinates of Campin et al. (2008), which allows the ice to depress the ocean surface according to its thickness and buoyancy.

A few comments regarding the robustness of our results against choice of forcing, integration period, and horizontal resolution follow. Strictly speaking, our results refer to an 8-year integration with $18 \mathrm{~km}$ horizontal grid spacing. We find that the differences between the solutions have an obvious trend after the first season but that this trend flattens out after a few seasons. We do not expect the differences to increase dramatically with additional integration time, since the simulated multi-year sea ice has reached a quasi equilibrium. Surface atmospheric conditions are specified every 6 hours. Models with weaker ice can react more quickly to a change in wind forcing, therefore we speculate that the differences between EVP and LSOR integrations would change with different forcing: less variable wind forcing would lead to smaller differences, while larger fluctuations in the forcing would increase them. In the same way, we expect that with coarser grids, the ocean component is much less variable so that in this case one will only find smaller differences between ice models.

The MITgcm sea ice model enables, within the same code, the direct comparison of various widely used dynamics and thermodynamics model components. What sets apart the MITgcm sea ice model from other current-generation sea ice models is the ability to derive an accurate, stable, and efficient adjoint model using automatic differentiation source transformation tools. This capability is the topic of a companion, second paper. The adjoint model greatly facilitates and enhances exploration of the model's parameter space. It lays the foundation for coupled ocean and sea ice state estimation. 


\section{A Dynamics}

For completeness we provide more details on the ice dynamics of the sea-ice model. The momentum equations are

$$
m \frac{D \mathbf{u}}{D t}=-m f \mathbf{k} \times \mathbf{u}+\boldsymbol{\tau}_{\text {air }}+\boldsymbol{\tau}_{\text {ocean }}-m \nabla \phi(0)+\mathbf{F},
$$

where $m=m_{i}+m_{s}$ is the ice and snow mass per unit area; $\mathbf{u}=u \mathbf{i}+v \mathbf{j}$ is the ice velocity vector; $\mathbf{i}, \mathbf{j}$, and $\mathbf{k}$ are unit vectors in the $x, y$, and $z$ directions, respectively; $f$ is the Coriolis parameter; $\boldsymbol{\tau}_{\text {air }}$ and $\boldsymbol{\tau}_{\text {ocean }}$ are the wind-ice and ocean-ice stresses, respectively; $g$ is the gravity acceleration; $\nabla \phi(0)$ is the gradient (or tilt) of the sea surface height; $\phi(0)=g \eta+p_{a} / \rho_{0}+m g / \rho_{0}$ is the sea surface height potential in response to ocean dynamics $(g \eta)$, to atmospheric pressure loading $\left(p_{a} / \rho_{0}\right.$, where $\rho_{0}$ is a reference density) and a term due to snow and ice loading (Campin et al., 2008); and $\mathbf{F}=\nabla \cdot \sigma$ is the divergence of the internal ice stress tensor $\sigma_{i j}$. Advection of sea-ice momentum is neglected. The wind and ice-ocean stress terms are given by

$$
\begin{aligned}
\boldsymbol{\tau}_{\text {air }} & =\rho_{\text {air }} C_{\text {air }}\left|\mathbf{U}_{\text {air }}-\mathbf{u}\right| R_{\text {air }}\left(\mathbf{U}_{\text {air }}-\mathbf{u}\right), \\
\boldsymbol{\tau}_{\text {ocean }} & =\rho_{\text {ocean }} C_{\text {ocean }}\left|\mathbf{U}_{\text {ocean }}-\mathbf{u}\right| R_{\text {ocean }}\left(\mathbf{U}_{\text {ocean }}-\mathbf{u}\right),
\end{aligned}
$$

where $\mathbf{U}_{\text {air/ocean }}$ are the surface winds of the atmosphere and surface currents of the ocean, respectively; $C_{\text {air/ocean }}$ are air and ocean drag coefficients; $\rho_{\text {air/ocean }}$ are reference densities; and $R_{\text {air/ocean }}$ are rotation matrices that act on the wind/current vectors. In this paper both rotation angles are set to zero.

For an isotropic system the stress tensor $\sigma_{i j}(i, j=1,2)$ can be related to the ice strain rate and strength by a nonlinear viscous-plastic (VP) constitutive law (Hibler, 1979, Zhang and Hibler, 1997):

$$
\sigma_{i j}=2 \eta\left(\dot{\epsilon}_{i j}, P\right) \dot{\epsilon}_{i j}+\left[\zeta\left(\dot{\epsilon}_{i j}, P\right)-\eta\left(\dot{\epsilon}_{i j}, P\right)\right] \dot{\epsilon}_{k k} \delta_{i j}-\frac{P}{2} \delta_{i j}
$$

The ice strain rate is given by

$$
\dot{\epsilon}_{i j}=\frac{1}{2}\left(\frac{\partial u_{i}}{\partial x_{j}}+\frac{\partial u_{j}}{\partial x_{i}}\right) .
$$

The maximum ice pressure $P_{\max }$, a measure of ice strength, depends on both thickness $h$ and compactness (concentration) $c$ :

$$
P_{\max }=P^{*} c h e^{\left[C^{*} \cdot(1-c)\right]},
$$

with the constants $P^{*}$ and $C^{*}$; we use $P^{*}=27500 \mathrm{~N} \mathrm{~m}^{-2}$ and $C^{*}=20$. The nonlinear bulk and shear viscosities $\eta$ and $\zeta$ are functions of ice strain rate invariants and ice strength such that the principal components of the stress 
lie on an elliptical yield curve with the ratio of major to minor axis $e$ equal to 2 ; they are given by:

$$
\begin{aligned}
\zeta & =\min \left(\frac{P_{\max }}{2 \max \left(\Delta, \Delta_{\min }\right)}, \zeta_{\max }\right) \\
\eta & =\frac{\zeta}{e^{2}}
\end{aligned}
$$

with the abbreviation

$$
\Delta=\left[\left(\dot{\epsilon}_{11}^{2}+\dot{\epsilon}_{22}^{2}\right)\left(1+e^{-2}\right)+4 e^{-2} \dot{\epsilon}_{12}^{2}+2 \dot{\epsilon}_{11} \dot{\epsilon}_{22}\left(1-e^{-2}\right)\right]^{\frac{1}{2}} .
$$

In the simulations of this paper, the bulk viscosities are bounded above by imposing both a minimum $\Delta_{\min }=10^{-11} \mathrm{~s}^{-1}$ and a maximum $\zeta_{\max }=P_{\max } / \Delta^{*}$, where $\Delta^{*}=\left(5 \times 10^{12} / 2 \times 10^{4}\right) \mathrm{s}^{-1}$. For stress tensor computation the replacement pressure $P=2 \Delta \zeta$ (Hibler and Ip, 1995) is used so that the stress state always lies on the elliptic yield curve by definition.

In the so-called truncated ellipse method (experiment TEM) the shear viscosity $\eta$ is capped to suppress any tensile stress (Hibler and Schulson, 1997, Geiger et al., 1998):

$$
\eta=\min \left(\frac{\zeta}{e^{2}}, \frac{\frac{P}{2}-\zeta\left(\dot{\epsilon}_{11}+\dot{\epsilon}_{22}\right)}{\sqrt{\left(\dot{\epsilon}_{11}+\dot{\epsilon}_{22}\right)^{2}+4 \dot{\epsilon}_{12}^{2}}}\right) .
$$

In the current implementation, the VP-model is integrated with the semiimplicit line successive over relaxation (LSOR)-solver of Zhang and Hibler (1997), which allows for long time steps that, in our case, are limited by the explicit treatment of the Coriolis term. The explicit treatment of the Coriolis term does not represent a severe limitation because it restricts the time step to approximately the same length as in the ocean model where the Coriolis term is also treated explicitly.

Hunke and Dukowicz (1997) introduced an elastic contribution to the strain rate in order to regularize Eq. A.2 in such a way that the resulting elasticviscous-plastic (EVP) and VP models are identical at steady state,

$$
\frac{1}{E} \frac{\partial \sigma_{i j}}{\partial t}+\frac{1}{2 \eta} \sigma_{i j}+\frac{\eta-\zeta}{4 \zeta \eta} \sigma_{k k} \delta_{i j}+\frac{P}{4 \zeta} \delta_{i j}=\dot{\epsilon}_{i j} .
$$

The EVP-model uses an explicit time stepping scheme with a short time step. According to the recommendation of Hunke and Dukowicz (1997), the EVPmodel is stepped forward in time $\mathrm{O}(120)$ times within the physical ocean model time step, to allow for elastic waves to disappear. Because the scheme does not require a matrix inversion it is fast in spite of the small internal time step 
and simple to implement on parallel computers (Hunke and Dukowicz, 1997). For completeness, we repeat the equations for the components of the stress tensor $\sigma_{1}=\sigma_{11}+\sigma_{22}, \sigma_{2}=\sigma_{11}-\sigma_{22}$, and $\sigma_{12}$. Introducing the divergence $D_{D}=\dot{\epsilon}_{11}+\dot{\epsilon}_{22}$, and the horizontal tension and shearing strain rates, $D_{T}=$ $\dot{\epsilon}_{11}-\dot{\epsilon}_{22}$ and $D_{S}=2 \dot{\epsilon}_{12}$, respectively, and using the above abbreviations, the equations A.5 can be written as:

$$
\begin{aligned}
\frac{\partial \sigma_{1}}{\partial t}+\frac{\sigma_{1}}{2 T}+\frac{P}{2 T} & =\frac{P}{2 T \Delta} D_{D} \\
\frac{\partial \sigma_{2}}{\partial t}+\frac{\sigma_{2} e^{2}}{2 T} & =\frac{P}{2 T \Delta} D_{T} \\
\frac{\partial \sigma_{12}}{\partial t}+\frac{\sigma_{12} e^{2}}{2 T} & =\frac{P}{4 T \Delta} D_{S}
\end{aligned}
$$

Here, the elastic parameter $E$ is redefined in terms of a damping time scale $T$ for elastic waves

$$
E=\frac{\zeta}{T}
$$

$T=E_{0} \Delta t$ with the tunable parameter $E_{0}<1$ and the external (long) time step $\Delta t$. In experiment C-EVP-10 use $E_{0}=\frac{1}{3}$ which is close to value of 0.36 used by Hunke (2001). In experiment C-EVP-03 we use $E_{0}=\frac{1}{10}$ resulting in $T=120 \mathrm{~s}$ for our choice of $\Delta t$.

\section{B Finite-volume discretization of the stress tensor divergence}

On an Arakawa $\mathrm{C}$ grid, ice thickness and concentration and thus ice strength $P$ and bulk and shear viscosities $\zeta$ and $\eta$ are naturally defined at C-points in the center of the grid cell. Discretization requires only averaging of $\zeta$ and $\eta$ to vorticity or Z-points at the bottom left corner of the cell to give $\bar{\zeta}^{Z}$ and $\bar{\eta}^{Z}$. In the following, the superscripts indicate location at $\mathrm{Z}$ or $\mathrm{C}$ points, distance across the cell $(\mathrm{F})$, along the cell edge $(\mathrm{G})$, between $u$-points $(\mathrm{U}), v$-points $(\mathrm{V})$, and C-points $(\mathrm{C})$. The control volumes of the $u$ - and $v$-equations in the grid cell at indices $(i, j)$ are $A_{i, j}^{w}$ and $A_{i, j}^{s}$, respectively. With these definitions (which follow the model code documentation at http://mitgcm.org except that vorticity or $\zeta$-points have been renamed to Z-points in order to avoid 
confusion with the bulk viscosity $\zeta$ ), the strain rates are discretized as:

$$
\begin{aligned}
& \dot{\epsilon}_{11}=\partial_{1} u_{1}+k_{2} u_{2} \\
&=>\left(\epsilon_{11}\right)_{i, j}^{C}=\frac{u_{i+1, j}-u_{i, j}}{\Delta x_{i, j}^{F}}+k_{2, i, j}^{C} \frac{v_{i, j+1}+v_{i, j}}{2} \\
& \dot{\epsilon}_{22}= \partial_{2} u_{2}+k_{1} u_{1} \\
&=>\left(\epsilon_{22}\right)_{i, j}^{C}= \frac{v_{i, j+1}-v_{i, j}}{\Delta y_{i, j}^{F}}+k_{1, i, j}^{C} \frac{u_{i+1, j}+u_{i, j}}{2} \\
& \dot{\epsilon}_{12}=\dot{\epsilon}_{21}= \frac{1}{2}\left(\partial_{1} u_{2}+\partial_{2} u_{1}-k_{1} u_{2}-k_{2} u_{1}\right) \\
&=>\left(\epsilon_{12}\right)_{i, j}^{Z}= \frac{1}{2}\left(\frac{v_{i, j}-v_{i-1, j}}{\Delta x_{i, j}^{V}}+\frac{u_{i, j}-u_{i, j-1}}{\Delta y_{i, j}^{U}}\right. \\
&\left.-k_{1, i, j}^{Z} \frac{v_{i, j}+v_{i-1, j}}{2}-k_{2, i, j}^{Z} \frac{u_{i, j}+u_{i, j-1}}{2}\right),
\end{aligned}
$$

so that the diagonal terms of the strain rate tensor are naturally defined at C-points and the symmetric off-diagonal term at Z-points. No-slip boundary conditions $\left(u_{i, j-1}+u_{i, j}=0\right.$ and $v_{i-1, j}+v_{i, j}=0$ across boundaries $)$ are implemented via "ghost-points"; for free slip boundary conditions $\left(\epsilon_{12}\right)^{Z}=0$ on boundaries.

For a spherical polar grid, the coefficients of the metric terms are $k_{1}=0$ and $k_{2}=-\tan \phi / a$, with the spherical radius $a$ and the latitude $\phi ; \Delta x_{1}=\Delta x=$ $a \cos \phi \Delta \lambda$, and $\Delta x_{2}=\Delta y=a \Delta \phi$. For a general orthogonal curvilinear grid as used in this paper, $k_{1}$ and $k_{2}$ can be approximated by finite differences of the cell widths:

$$
\begin{aligned}
k_{1, i, j}^{C} & =\frac{1}{\Delta y_{i, j}^{F}} \frac{\Delta y_{i+1, j}^{G}-\Delta y_{i, j}^{G}}{\Delta x_{i, j}^{F}} \\
k_{2, i, j}^{C} & =\frac{1}{\Delta x_{i, j}^{F}} \frac{\Delta x_{i, j+1}^{G}-\Delta x_{i, j}^{G}}{\Delta y_{i, j}^{F}} \\
k_{1, i, j}^{Z} & =\frac{1}{\Delta y_{i, j}^{U}} \frac{\Delta y_{i, j}^{C}-\Delta y_{i-1, j}^{C}}{\Delta x_{i, j}^{V}} \\
k_{2, i, j}^{Z} & =\frac{1}{\Delta x_{i, j}^{V}} \frac{\Delta x_{i, j}^{C}-\Delta x_{i, j-1}^{C}}{\Delta y_{i, j}^{U}}
\end{aligned}
$$

The stress tensor is given by the constitutive viscous-plastic relation $\sigma_{\alpha \beta}=$ $2 \eta \dot{\epsilon}_{\alpha \beta}+\left[(\zeta-\eta) \dot{\epsilon}_{\gamma \gamma}-P / 2\right] \delta_{\alpha \beta}$ (Hibler, 1979). The stress tensor divergence $(\nabla \sigma)_{\alpha}=\partial_{\beta} \sigma_{\beta \alpha}$, is discretized in finite volumes. This conveniently avoids dealing with further metric terms, as these are "hidden" in the differential cell 
widths. For the $u$-equation $(\alpha=1)$ we have:

746

747

748

749

750

751

with

$$
\begin{aligned}
(\nabla \sigma)_{1}: & \frac{1}{A_{i, j}^{w}} \int_{\text {cell }}\left(\partial_{1} \sigma_{11}+\partial_{2} \sigma_{21}\right) d x_{1} d x_{2} \\
= & \frac{1}{A_{i, j}^{w}}\left\{\left.\int_{x_{2}}^{x_{2}+\Delta x_{2}} \sigma_{11} d x_{2}\right|_{x_{1}} ^{x_{1}+\Delta x_{1}}+\left.\int_{x_{1}}^{x_{1}+\Delta x_{1}} \sigma_{21} d x_{1}\right|_{x_{2}} ^{x_{2}+\Delta x_{2}}\right\} \\
\approx & \frac{1}{A_{i, j}^{w}}\left\{\left.\Delta x_{2} \sigma_{11}\right|_{x_{1}} ^{x_{1}+\Delta x_{1}}+\left.\Delta x_{1} \sigma_{21}\right|_{x_{2}} ^{x_{2}+\Delta x_{2}}\right\} \\
= & \frac{1}{A_{i, j}^{w}}\left\{\left(\Delta x_{2} \sigma_{11}\right)_{i, j}^{C}-\left(\Delta x_{2} \sigma_{11}\right)_{i-1, j}^{C}\right. \\
\quad & \left.\quad\left(\Delta x_{1} \sigma_{21}\right)_{i, j+1}^{Z}-\left(\Delta x_{1} \sigma_{21}\right)_{i, j}^{Z}\right\}
\end{aligned}
$$

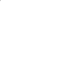


Similarly, we have for the $v$-equation $(\alpha=2)$ :

$$
\begin{aligned}
&(\nabla \sigma)_{2}: \frac{1}{A_{i, j}^{s}} \int_{\text {cell }}\left(\partial_{1} \sigma_{12}+\partial_{2} \sigma_{22}\right) d x_{1} d x_{2} \\
&= \frac{1}{A_{i, j}^{s}}\left\{\left.\int_{x_{2}}^{x_{2}+\Delta x_{2}} \sigma_{12} d x_{2}\right|_{x_{1}} ^{x_{1}+\Delta x_{1}}+\left.\int_{x_{1}}^{x_{1}+\Delta x_{1}} \sigma_{22} d x_{1}\right|_{x_{2}} ^{x_{2}+\Delta x_{2}}\right\} \\
& \approx \frac{1}{A_{i, j}^{s}}\left\{\left.\Delta x_{2} \sigma_{12}\right|_{x_{1}} ^{x_{1}+\Delta x_{1}}+\left.\Delta x_{1} \sigma_{22}\right|_{x_{2}} ^{x_{2}+\Delta x_{2}}\right\} \\
&= \frac{1}{A_{i, j}^{s}}\left\{\left(\Delta x_{2} \sigma_{12}\right)_{i+1, j}^{Z}-\left(\Delta x_{2} \sigma_{12}\right)_{i, j}^{Z}\right. \\
&\left.\quad+\left(\Delta x_{1} \sigma_{22}\right)_{i, j}^{C}-\left(\Delta x_{1} \sigma_{22}\right)_{i, j-1}^{C}\right\}
\end{aligned}
$$

with

$$
\begin{aligned}
\left(\Delta x_{1} \sigma_{12}\right)_{i, j}^{Z}= & \Delta y_{i, j}^{U} \bar{\eta}_{i, j}^{Z} \frac{u_{i, j}-u_{i, j-1}}{\Delta y_{i, j}^{U}} \\
& +\Delta y_{i, j}^{U} \bar{\eta}_{i, j}^{Z} \frac{v_{i, j}-v_{i-1, j}}{\Delta x_{i, j}^{V}} \\
& -\Delta y_{i, j}^{U} \bar{\eta}_{i, j}^{Z} k_{2, i, j}^{Z} \frac{u_{i, j}+u_{i, j-1}}{2} \\
& -\Delta y_{i, j}^{U} \bar{\eta}_{i, j}^{Z} k_{1, i, j}^{Z} \frac{v_{i, j}+v_{i-1, j}}{2} \\
\left(\Delta x_{2} \sigma_{22}\right)_{i, j}^{C}= & \Delta x_{i, j}^{F}(\zeta-\eta)_{i, j}^{C} \frac{u_{i+1, j}-u_{i, j}}{\Delta x_{i, j}^{F}} \\
& +\Delta x_{i, j}^{F}(\zeta-\eta)_{i, j}^{C} k_{2, i, j}^{C} \frac{v_{i, j+1}+v_{i, j}}{2} \\
& +\Delta x_{i, j}^{F}(\zeta+\eta)_{i, j}^{C} \frac{v_{i, j+1}-v_{i, j}}{\Delta y_{i, j}^{F}} \\
& +\Delta x_{i, j}^{F}(\zeta+\eta)_{i, j}^{C} k_{1, i, j}^{C} \frac{u_{i+1, j}+u_{i, j}}{2} \\
& -\Delta x_{i, j}^{F} \frac{P}{2}
\end{aligned}
$$

\section{Acknowledgements}

We thank Jinlun Zhang for providing the original B-grid code and for many helpful discussions. ML thanks Elizabeth Hunke for multiple explanations and Sergey Danilov and Rüdiger Gerdes for comments on the manuscript. This work was supported by NSF award ARC-0804150, DOE award DE-FG0208ER64592, and NASA award NNG06GG98G. It is a contribution to the ECCO2 project sponsored by the NASA Modeling Analysis and Prediction 
(MAP) program and to the ECCO-GODAE project sponsored by the National Oceanographic Partnership Program (NOPP). Computing resources were provided by NASA/ARC, NCAR/CSL, and JPL/SVF.

\section{References}

Aagaard, K., Carmack, E. C., 1989. The role of sea ice and other fresh waters in the Arctic circulation. J. Geophys. Res. 94 (C10), 14,485-14,498.

Adcroft, A., Campin, J.-M., 2004. Rescaled height coordinates for accurate representation of free-surface flows in ocean circulation models. Ocean Modelling 7 (3-4), 269-284.

Adcroft, A., Campin, J.-M., Hill, C. N., Marshall, J. C., 2004. Implementation of an atmosphere-ocean general circulation model on the expanded spherical cube. Mon. Weather Rev. 132 (12), 2845-2863.

Adcroft, A., Hill, C., Marshall, J., 1997. Representation of topography by shaved cells in a height coordinate ocean model. Mon. Weather Rev. 125 (9), 2293-2315.

Adcroft, A., Marshall, D., 1998. How slippery are piecewise-constant coastlines in numerical ocean models? Tellus 50A, 95-108.

Agnew, T., Lambe, A., Long, D., 2008. Estimating sea ice area flux across the Canadian Arctic Archipelago using enhanced AMSR-E. J. Geophys. Res. 113, C10011.

Bouillon, S., Maqueda, M. Á. M., Legat, V., Fichefet, T., 2009. An elasticviscous-plastic sea ice model formulated on Arakawa B and $\mathrm{C}$ grids. Ocean Modelling 27 (3-4), 174-184.

Bryan, K., Lewis, L. J., 1979. A water mass model of the world ocean. J. Geophys. Res. 84 (C5), 2503-2517.

Campin, J.-M., Marshall, J., Ferreira, D., 2008. Sea-ice ocean coupling using a rescaled vertical coordinate $\mathrm{z}^{*}$. Ocean Modelling 24 (1-2), 1-14.

Cavalieri, D. J., Parkinson, C., 2008. Antarctic sea ice variability and trends, 1979-2006. J. Geophys. Res. 113, C07004.

Daru, V., Tenaud, C., 2004. High order one-step monotonicity-preserving schemes for unsteady compressible flow calculations. J. Comput. Phys. 193 (2), 563-594.

Dey, B., 1981. Monitoring winter sea ice dynamics in the Canadian Arctic with NOAA-TIR images. J. Geophys. Res. 86 (C4), 3223-3235.

Fenty, I., 2010. State estimation of the Labrador Sea with a coupled ocean/seaice adjoint model. Ph.D. thesis, MIT, Program in Atmosphere, Ocean and Climate (PAOC), Cambridge (MA), USA.

Fox-Kemper, B., Menemenlis, D., 2008. Can large eddy simulation techniques improve mesoscale rich ocean models? In: Hecht, M., Hasumi, H. (Eds.), Ocean Modeling in an Eddying Regime. AGU, Washington, D.C., pp. 319338. 
Geiger, C. A., Hibler, III, W. D., Ackley, S. F., 1998. Large-scale sea ice drift and deformation: Comparison between models and observations in the western Weddell Sea during 1992. J. Geophys. Res. 103 (C10), 21893-21913.

Griewank, A., 2000. Evaluating Derivatives. Principles and Techniques of Algorithmic Differentiation. Vol. 19 of Frontiers in Applied Mathematics. SIAM, Philadelphia.

Hansen, J., Russell, G., Rind, D., Stone, P., Lacis, A., Lebedeff, S., Ruedy, R., Travis, L., 1983. Efficient three-dimensional global models for climate studies: Models I and II. Mon. Weather Rev. 111, 609-662.

Harder, M., Fischer, H., 1999. Sea ice dynamics in the Weddell Sea simulated with an optimzed model. J. Geophys. Res. 104 (C5), 11,151-11,162.

Heimbach, P., January 2008. The MITgcm/ECCO adjoint modelling infrastructure. CLIVAR Exchanges 44 (Volume 13, No. 1), 13-17.

Hibler, III, W. D., 1979. A dynamic thermodynamic sea ice model. J. Phys. Oceanogr. 9 (4), 815-846.

Hibler, III, W. D., 1980. Modeling a variable thickness sea ice cover. Mon. Weather Rev. 108 (2), 1943-1973.

Hibler, III, W. D., 1984. The role of sea ice dynamics in modeling $\mathrm{CO}_{2}$ increases. In: Hansen, J. E., Takahashi, T. (Eds.), Climate processes and climate sensitivity. Vol. 29 of Geophysical Monograph. AGU, Washington, D.C., pp. $238-253$.

Hibler, III, W. D., Bryan, K., 1987. A diagnostic ice-ocean model. J. Phys. Oceanogr. 17 (7), 987-1015.

Hibler, III, W. D., Ip, C. F., 1995. The effect of sea ice rheology on Arctic buoy drift. In: Dempsey, J. P., Rajapakse, Y. D. S. (Eds.), Ice Mechanics. Vol. 204 of AMD. Am. Soc. of Mech. Eng., New York, pp. 255-264.

Hibler, III, W. D., Schulson, E. M., 1997. On modeling sea-ice fracture and flow in numerical investigations of climate. Ann. Glaciol. 25, 26-32.

Holloway, G., Dupont, F., Golubeva, E., Häkkinen, S., Hunke, E., Jin, M., Karcher, M., Kauker, F., Maltrud, M., Morales Maqueda, M. A., Maslowsksi, W., Platov, G., Stark, D., Steele, M., Suzuki, T., Wang, J., Zhang, J., 2007. Water properties and circulation in Arctic Ocean models. J. Geophys. Res. 112 (C04S03).

Huffman, G. J., Adler, R. F., Morrissey, M. M., Curtis, S., Joyce, R., McGavock, B., Susskind, J., 2001. Global precipitation at one-degree daily resolution from multi-satellite observations. J. Hydrometeor. 2, 36-50.

Hundsdorfer, W., Trompert, R. A., 1994. Method of lines and direct discretization: a comparison for linear advection. Applied Numerical Mathematics 13 (6), 469-490.

Hunke, E. C., 2001. Viscous-plastic sea ice dynamics with the EVP model: Linearization issues. J. Comp. Phys. 170, 18-38.

Hunke, E. C., Dukowicz, J. K., 1997. An elastic-viscous-plastic model for sea ice dynamics. J. Phys. Oceanogr. 27, 1849-1867.

Hunke, E. C., Dukowicz, J. K., 2002. The elastic-viscous-plastic sea ice dynamics model in general orthogonal curvilinear coordinates on a sphere- 
incorporation of metric terms. Mon. Weather Rev. 130 (7), 1847-1865.

Hunke, E. C., Zhang, Y., 1999. A comparison of sea ice dynamics models at high resolution. Mon. Weather Rev. 127, 396-408.

Ip, C. F., Hibler, III, W. D., Flato, G. M., 1991. On the effect of rheology on seasonal sea-ice simulations. Ann. Glaciol. 15, 17-25.

Jackett, D. R., McDougall, T. J., 1995. Minimal adjustment of hydrographic profiles to achieve static stability. J. Atmos. Oceanic Technol. 12 (2), 381389.

Kreyscher, M., Harder, M., Lemke, P., Flato, G. M., 2000. Results of the Sea Ice Model Intercomparison Project: Evaluation of sea ice reology schemes for use in climate simulations. J. Geophys. Res. 105 (C5), 11,299-11,320.

Kwok, R., 2005. Variability of Nares Strait ice flux. Geophys. Res. Lett. 32 (L24502).

Kwok, R., Hunke, E. C., Maslowski, W., Menemenlis, D., Zhang, J., 2008. Variability of sea ice simulations assessed with RGPS kinematics. J. Geophys. Res. 113 (C11012).

Large, W., Yeager, S., 2004. Diurnal to decadal global forcing for ocean and sea-ice models: the data sets and flux climatologies. Technical Note NCAR/TN-460+STR, NCAR, Boulder, CO.

Large, W. G., McWilliams, J. C., Doney, S., 1994. Oceanic vertical mixing: A review and a model with a nonlocal boundary layer parameterization. Rev. Geophysics 32 (4), 363-403.

Large, W. G., Nurser, A. J. G., 2001. Ocean surface water mass transformation. In: Siedler, G., Church, J., Gould, J. (Eds.), Ocean Circulation and Climate. Academic, San Diego, Calif., pp. 317-336.

Leith, C. E., 1996. Stochastic models of chaotic systems. Physica D 98, 481491.

Lemieux, J.-F., Tremblay, B., 2009. Numerical convergence of viscous-plastic sea ice models. J. Geophys. Res. 114 (C05009).

Lemieux, J.-F., Tremblay, B., Thomas, S., Sedláček, J., Mysak, L. A., 2008. Using the preconditioned Generalized Minimum RESidual (GMRES) method to solve the sea-ice momentum equation. J. Geophys. Res. 113 (C10004).

Lemke, P., Ren, J., Alley, R. B., Allison, I., Carrasco, J., Flato, G., Fujii, Y., Kaser, G., Mote, P., Thomas, R. H., Zhang, T., 2007. Observations: Changes in snow, ice and frozen ground. In: Solomon, S., Qin, D., Manning, M., Chen, Z., Marquis, M., Averyt, K. B., Tignor, M., Miller, H. L. (Eds.), Climate Change 2007: The Physical Science Basis. Contribution of Working Group I to the Fourth Assessment Report of the Intergovernmental Panel on Climate Change. Cambridge University Press, Cambridge, United Kingdom and New York, NY, USA, pp. 338-383.

Leppäranta, M., 1983. A growth model for black ice, snow ice and snow thickness in subarctic basins. Nordic Hydrology 14, 59-70.

Lohmann, G., Gerdes, R., 1998. Sea ice effects on the sensitivity of the thermohaline circulation in simplified atmosphere-ocean-sea ice models. J. Climate 11, 2789-2803. 
Manabe, S., Bryan, K., Spelman, M. J., 1979. A global ocean-atmosphere climate model with seasonal variation for future studies of climate sensitivity. Dyn. Atmos. Oceans 3 (393-426).

Marshall, J., Adcroft, A., Hill, C., Perelman, L., Heisey, C., 1997a. A finitevolume, incompressible Navier Stokes model for studies of the ocean on parallel computers. J. Geophys. Res. 102 (C3), 5753-5766.

Marshall, J., Hill, C., Perelman, L., Adcroft, A., 1997b. Hydrostatic, quasihydrostatic, and nonhydrostatic ocean modeling. J. Geophys. Res. 102 (C3), $5733-5752$.

Martin, T., Gerdes, R., 2007. Sea ice drift variability in Arctic Ocean Model Intercomparison Project models and observations. J. Geophys. Res. 112 (C04S10).

McPhee, M. G., 1992. Turbulent heat flux in the upper ocean under sea ice. J. Geophys. Res. 97 (C4), 5365-5379.

Mellor, G. L., McPhee, M. G., Steele, M., 1986. Ice-seawater turbulent boundary layer interaction with melting or freezing. J. Phys. Oceanogr. 16 (11), $1829-1846$.

Menemenlis, D., Hill, C., Adcroft, A., Campin, J.-M., Cheng, B., Ciotti, B., Fukumori, I., Koehl, A., Heimbach, P., Henze, C., Lee, T., Stammer, D., Taft, J., Zhang, J., 2005. NASA supercomputer improves prospects for ocean climate research. Eos Trans. AGU 86 (9), 89, 95-96.

Merryfield, W. J., Holloway, G., 2003. Application of an accurate advection algorithm to sea-ice modelling. Ocean Modelling 5 (1), 1-15.

URL http://www.sciencedirect.com/science/article/B6VPS-45XT\% 1F8-1/2/3cb5a53883cbb37eec41e7418910082e

MITgcm Group, 2002. MITgcm Release 1 Manual. Online documentation, MIT/EAPS, Cambridge, MA 02139, USA, http://mitgcm.org/sealion/ online_documents/manual.html.

Notz, D., McPhee, M. G., Worster, M. G., Maykut, G. A., Schlünzen, K. H., , Eicken, H., 2003. Impact of underwater-ice evolution on Arctic summer sea ice. J. Geophys. Res. 108 (C7), 3223.

Parkinson, C. L., Cavalieri, D., 2008. Arctic sea ice variability and trends, 1979-2006. J. Geophys. Res. 113, C07003.

Parkinson, C. L., Washington, W. M., Jan. 1979. A Large-Scale Numerical Model of Sea Ice. J. Geophys. Res. 84 (C1), 311-337.

Paulson, C. A., Simpson, J. J., 1977. Irradiance measurements in the upper ocean. J. Phys. Oceanogr. 7 (6), 952-956.

Proshutinsky, A., Kowalik, Z., 2007. Preface to special section on Arctic Ocean Model Intercomparison Project (AOMIP) studies and results. J. Geophys. Res. 112 (C4S01).

Roe, P., 1985. Some contributions to the modelling of discontinuous flows. In: Engquist, B., Osher, S., Somerville, R. (Eds.), Large-Scale Computations in Fluid Mechanics. Vol. 22 of Lectures in Applied Mathematics. American Mathematical Society, pp. 163-193.

Semtner, Jr., A. J., 1976. A model for the thermodynamic growth of sea ice 
in numerical investigations of climate. J. Phys. Oceanogr. 6, 379-389.

Semtner, Jr., A. J., 1984. On modelling the seasonal thermodynamic cycle of sea ice in studies of climatic change. Clim. Change 6 (1), 27-37.

Serreze, M. C., Barrett, A. P., Slater, A. G., Woodgate, R. A., Aagaard, K., Lammers, R. B., Steele, M., Moritz, R., Meredith, M., Lee, C. M., 2006. The large-scale freshwater cycle of the Arctic. J. Geophys. Res. 111 (C11010).

Serreze, M. C., Holland, M. M., J., S., 2007. Perspectives on the Arctic's shrinking sea-ice cover. Science 315, 1533-1536.

Smith, W. H. F., Sandwell, D. T., 1997. Global sea floor topography from satellite altimetry and ship depth soundings. Science 277 (5334), 1956-1962.

Stammer, D., Wunsch, C., Giering, R., Eckert, C., Heimbach, P., Marotzke, J., Adcroft, A., Hill, C., Marshall, J., 2002a. The global ocean circulation and transports during 1992 - 1997, estimated from ocean observations and a general circulation model. J. Geophys. Res. 107(C9), 3118.

Steele, M., Morley, R., Ermold, W., 2001. PHC: A global ocean hydrography with a high quality arctic ocean. J. Clim. 14, 2079-2087.

Tang, C. C. L., Ross, C. K., Yao, T., Petrie, B., DeTracey, B. M., Dunlap, E., December 2004. The circulation, water masses and sea-ice of Baffin Bay. Prog. Oceanogr. 63 (4), 183-228.

Timmermann, R., Beckmann, A., Hellmer, H. H., 2002. Simulation of ice-ocean dynamics in the Weddell Sea. Part I: Model configuration and validation. J. Geophys. Res. 107 (C3), 3024.

Tremblay, L.-B., Mysak, L. A., 1997. Modeling sea ice as a granular material, including the dilatancy effect. J. Phys. Oceanogr. 27, 2342-2360.

Uppala, S. M., Kållberg, P. W., Simmons, A. J., Andrae, U., da Costa Bechtold, V., Fiorino, M., Gibson, J. K., Haseler, J., Hernandez, A., Kelly, G. A., Li, X., Onogi, K., Saarinen, S., Sokka, N., Allan, R., Andersson, E., Arpe, K., Balmaseda, M., Beljaars, A., van de Berg, L., Bidlot, J., Bormann, N., Caires, S., Chevallier, F., Dethof, A., Dragosavac, M., Fisher, M., Fuentes, M., Hagemann, S., Hólm, E., Hoskins, B., Isaksen, L., Janssen, P., Jenne, R., McNally, A., Mahfouf, J.-F., Morcrette, J.-J., Rayner, N., Saunders, R., Simon, P., Sterl, A., Trenberth, K., Untch, A., Vasiljevic, D., Viterbo, P., Woollen, J., 2005. The ERA-40 re-analysis. Q. J. R. Meteorol. Soc. 131, 2961-3012.

Winton, M., 2000. A reformulated three-layer sea ice model. J. Atmos. Oceanic Technol. 17 (4), 525-531.

Zhang, J., Hibler, III, W. D., 1997. On an efficient numerical method for modeling sea ice dynamics. J. Geophys. Res. 102 (C4), 8691-8702.

Zhang, J., Hibler, III, W. D., Steele, M., Rothrock, D. A., 1998. Arctic iceocean modeling with and without climate restoring. J. Phys. Oceanogr. 28 (2), 191-217. 